\title{
Curly Arrows, Electron Flow, and Reaction Mechanisms from the Perspective of the Bonding Evolution Theory
}

\author{
Juan Andrés ${ }^{1 *}$, Patricio González-Navarrete ${ }^{1}$, Vicent Sixte Safont ${ }^{1}$, and Bernard Silvi ${ }^{2}$ \\ ${ }^{1}$ Departament de Química Física i Analítica, Universitat Jaume I, 12071 Castelló, Spain \\ ${ }^{2}$ Sorbonne Universités, UPMC, Univ Paris 06, UMR 7616, Laboratoire de Chimie Théorique, case \\ courrier 137, 4 place Jussieu, F-75752 Paris, France \\ *Corresponding author: andres@qfa.uji.es
}

\begin{abstract}
Despite the usefulness of curly arrows in chemistry, their relationship with real electron density flows is still imprecise, and even their direct connection to quantum chemistry is still controversial. The paradigmatic description - from first principles - of the mechanistic aspects of a given chemical process is based mainly on the relative energies and geometrical changes at the stationary points of the potential energy surface along the reaction pathway; however, it is not sufficient to describe chemical systems in terms of bonding aspects. Probing the electron density distribution during a chemical reaction can provide important insights, enabling us to understand and control chemical reactions. This aim has required an extension of the relationships between the concepts of traditional chemistry and those of quantum mechanics. Bonding evolution theory (BET), which combines the topological analysis of the electron localization function (ELF) and Thom's catastrophe theory (CT), provides a powerful method that offers insight into the molecular mechanism of chemical rearrangements. In agreement with the laws of physical and aspects of quantum theory, BET can be considered an appropriate tool to tackle chemical reactivity with a wide range of possible applications.

In this work, BET is applied to address a long-standing problem: the ability to monitor the flow of electron density. BET analysis shows a connection between quantum mechanics and bond making/forming processes. Likewise, the present approach retrieves the classical curly arrows used to describe the rearrangements of chemical bonds and provides detailed physical grounds for this type of representation. We demonstrate this procedure using the test set of prototypical examples of thermal ring apertures, and the degenerated Cope rearrangement of semibullvalene.
\end{abstract}




\section{Concept of Chemical Bond}

Chemistry is the science of atoms, molecules, and matter. Chemists are capable of obtaining a wide range of molecules and determining their structures and transformations, even at extraordinary levels of complexity, using sophisticated experimental techniques as well as accurate first-principle calculations. This type of work makes it possible to elucidate how atoms, as constitutive entities, hold together by chemical bonds in order to understand the 3D rearrangements of atoms in molecules and solids. In general terms, a molecule possesses one stable structure with a defined geometry under a given condition that is determined by its chemical bond.

In chemistry, theoretical concepts play an important role and useful qualitative concepts such as the chemical bond appeared very early in the chemical literature. The chemical bond is one of the most prominent concepts in chemistry to describe and understand the structure of molecules and their chemical reactivity. It is employed in all fields of chemistry and on all levels, from school education to research. However, the concept of chemical bond is a legacy from the development of structural chemistry during the $19^{\text {th }}$ century, and it is ultimately determined by the representation of the matter one can have. As chemists, we are primarily concerned with composition in terms of elemental atoms (in a molecule). To consider the structural formula as graphics, atoms are shown at vertices, linked by straight lines (bonds). Removal of a bond increases the number of independent species by one or opens at least one cycle. The possible numbers of bonds around a center are determined by the group of the elemental atom. The resulting representation is that of elemental atoms linked by bonds. Building rules have been proposed by Lewis based on a partition of the electrons between kernels and valence shells, and magic numbers rules, namely the duet and octet rules, which have to be fulfilled by bonding and non-bonding electron pairs. Lewis's original approach has been further complemented by expended octet rules, ${ }^{1-4}$ mesomery, ${ }^{5,} 6$ by methods providing the spatial arrangement and the size of electron pairs, ${ }^{7-11}$ and so on. A closer look, however, often reveals that attempting to quantify the concept of chemical bond is futile and it is still awaiting a solution. ${ }^{12}$

Owing to the still ambiguous definition of the concept of chemical bond, like other concepts in chemistry, ${ }^{13}$ a great deal of effort has been devoted to clarifying its intrinsic nature. However, this concept is not directly associated with experimentally observable values, which lack unique quantitative assessments. ${ }^{14}$ In the special issue of the Journal of Computational Chemistry in 2007 entitled "90 Years of Chemical Bonding", published with this aim, ${ }^{15}$ Frenking and Krapp ${ }^{16}$ compared the chemical bond to a "unicorn", as a "mythical but useful creature which brings law and order in an otherwise chaotic and disordered world" where everyone knows what they look like despite nobody ever having seen one. ${ }^{17,} 18$ This line of reasoning is similar to Coulson's comment: "Sometimes it seems to me that a bond between two atoms has become so real, so tangible, so 
friendly, that I can almost see it. Then I awake with a little shock, for a chemical bond is not a real thing. It does not exist. No one has ever seen one. No one ever can. It is a figment of our own imagination". ${ }^{19}$ Likewise, chemical bonds have been described as "noumenon" rather than as "phenomenon". ${ }^{20-22}$

In chemistry as in other scientific disciplines, there is no place for ambiguity. The definition of a concept such as chemical bond must be clear and unequivocal; building those definitions is the raison d'être for the existence of the IUPAC. Unfortunately, like many other fundamental concepts in chemistry, the concept of chemical bond lacks a precise and unique definition and, even worse, no quantum mechanical "bond operator" can provide a conventional expectation value. In contrast, as quoted in Ritter's paper, ${ }^{23}$ Nobel Laureate Roald Hoffmann says: "Push the chemical concept to its limits. Be aware of the different experimental and theoretical measures out there. Accept that (at the limits) a bond will be a bond by some criteria, maybe not others. Respect chemical tradition, relax, and instead of wringing your hands about how terrible it is that this concept cannot be unambiguously defined, have fun with the fuzzy richness of the idea".

In many fields, advanced theories are supported by two important milestones: a mathematical structure/formalism disclosing the basic entities of theory together with their mathematical relationships, and an interpretative recipe of the basic entities of the theory. Moreover, it is important to recognize that the connection between the mathematical formalism of a theory and its interpretation is always subtle. This problem can be traced back to the lack of a clear and unambiguous definition of a bond in quantum mechanics, and a plethora of interpretations have been introduced with various "meanings" of the "mathematical symbols/entities" of the theory. ${ }^{24}$

From this quandary, two opposing attitudes can be envisaged. On the one hand there is the old and negative statement of the French mathematician R. Thom: "Il me faut cependant avouer que la chimie proprement dite ne m'a jamais beaucoup intéressée. Pourquoi? Peut-être parce que des notions telles que celles de valence, de liaisons chimique etc., ont toujours semblées peu claires du point de vue conceptuel" (I should admit that chemistry never really interested me. Why? Perhaps because notions such as that of valence, chemical bond, etc., always appeared unclear from the conceptual point of view). On the other hand, there is the more actual and pragmatic comment by Álvarez et al.: "Chemistry has done more than well in a universe of structure and function on the molecular level with just this imperfectly defined concept of a chemical bond. Or maybe it has done so well precisely because the concept is flexible and fuzzy". ${ }^{25}$ However, it is important to note that scientific arguments, debates, and controversy are at the heart of chemistry. This situation has been clearly stated in the very recent paper entitled "The Nature of the Fourth Bond in the Ground State of $\mathrm{C}_{2}$ : The Quadruple Bond Conundrum" by Shaik et al. ${ }^{26}$, where the authors recognize that they 
find themselves before a "Rashomon effect" (see en.wikipedia.org/wiki/Rashomon effect), in which the bonding picture risks becoming too fuzzy to be constructive anymore.

To describe the matter at the molecular level, we can make a first universal statement: "matter is made of nuclei and electrons electrostatically interacting". To address this statement, quantum mechanics allows the Hamiltonian to be written out in order to calculate energies and other observables, and to bring a large part of chemistry in line with Dirac's research program. Such a theory is predictive and is able to provide chemical explanations. Thanks to the density functional theory formalism, chemistry can account for external potential, which expresses the interaction between the nuclei and the electrons.

\section{Quantum Mechanics in Chemical Interpretation}

Quantum mechanics constitutes the fundamental framework underlying the theoretical study of molecular systems. The quantum-mechanical approach to chemical phenomena usually deals with very complex numerical algorithms for the approximate solution of the many-body Schrödinger equation. From a theoretical perspective, molecules are quantum matter for which structure is defined by a full specification of quantum numbers for the correlated electron and nuclear motion. Similarly, chemical reactions are transformations of the eigenstates of the reactant into those of the reaction products. In the context of quantum mechanics, a molecular process is described completely by the time-dependent state vector $|\Psi(\mathrm{t})\rangle$, which evolves according to Schrödinger's equation governing the simultaneous coupled motions of electrons and nuclei. In the most common instance, the process is taken to be electronically adiabatic (i.e., the light, fast electrons adjust instantaneously to the movements of the heavy, slow nuclei). To describe such a process, one typically invokes the Born-Oppenheimer approximation (BOA). ${ }^{27-29}$ From this approximation, the concept of potential energy surface (PES) is derived, which plays a central role in the theory and computational simulation of chemical structure and reactivity. This representation of the reaction mechanism is intuitively apprehended as a progression of states from reactants to products, where the electronic energy of the different states is described as a function of the positions of the nuclei in the coordinate-energy space ${ }^{30}$ Quantum chemical methods developed since the 1960s have made tremendous progress so that it is now possible to compute PES with a number of varying approximations. These range from semiempirical methods, ab initio Hartree-Fock approaches and density functional theory to higher computational levels such as multiconfigurational self-consistent field or complete active space second-order perturbation, thus yielding efficient predictions and accurate energies (better than fractions of a $\mathrm{kcal} \mathrm{mol}^{-1}$ ) for the thermodynamic and kinetic parameters of a sufficiently large number of chemical reactions. In the above context, chemical reactivity is determined by the potential energy landscape of the reacting 
species, and the course of a chemical reaction can be considered as an evolution of atoms on a PES. In this energy-based picture, a given chemical reaction can be viewed as a sequence of snapshots of a complex process in space and time. This type of modeling is without a doubt a very important tool for a deeper understanding of chemical reactions, and thus a key for building the knowledge base we need to be able to design chemical processes. However, as energy is a global quantity that contains all energy changes, such an energy-based partitioning of a chemical reaction misses mechanistic details, i.e., bond making/forming processes that are the essence of chemical reactivity. Particular interest has been focused on extracting information about the stationary points of the energy surface. In the BOA framework, minima on the $N$-dimensional PES for the nuclei can be identified with the classical picture of equilibrium structures of molecules, while saddle points can be related to transition states (TSs) and reaction rates. Within this approach, minima and saddle points have been fully characterized through the first and second derivatives of the energy (gradient and Hessian) over the positions of the nuclei.

A large number of computational studies of chemical reactions are based on the concept of the PES, while the main parameters in chemical kinetic models (equilibrium constants and rate coefficients) are increasingly derived from quantum mechanical calculations on the stationary points along the PES. Local minima, i.e., reactants, intermediates, and products, are generally easy to characterize due to simple bonding and also because the negative of the gradient along the PES always points downhill. Hence, reaction mechanisms can be modelled as minimum energy paths between stable configurations on a $3 \mathrm{~N}-6$ multidimensional PES. ${ }^{31-35}$

\section{Chemical Reactivity and Electron Density}

The nature of the bond determines the intrinsic chemical reactivity. However, the complexity of the electronic structure in the transient regime of emerging or breaking chemical bonds cannot be unambiguously defined in pure quantum theory, thus hindering the understanding of how atoms or molecules bond at the most fundamental level. Likewise, there is no unambiguous relationship between kinetics and reaction mechanism that can be used to predict the conditions for the favorable evolution of a given chemical process. Quantitatively, characterizing the fundamental basis of reaction pathway preference remains an elusive ideal to be reached in chemical reactivity, although recent advances in electron microscopy techniques have allowed direct observation of reactive intermediates despite their short lifetimes and high reactivities. ${ }^{36,} 37$ Thus, a better understanding of reaction mechanisms and product distributions can be achieved by molecular dynamics of reactions at or in the immediate vicinity of transition states, which can be complemented with experiments such as those performed by Polany ${ }^{38}$ and Brooks, ${ }^{39}$ the timeresolved pump-probe "femtochemistry" experiments pioneered by Zewail, ${ }^{40}$ or the negative ion 
photodetachment experiments of Neumark $^{41}$ and Lineberger. ${ }^{42}$ Thus, these experimental observations can be compared with predictions based on molecular simulations and/or transition state theory.

Electronic structure calculations have been used to help understand the chemical bond. Some of them were computed directly from calculated N-electron wave-functions, such as valence bond theory ${ }^{43}$ or natural bond orbitals, ${ }^{44}$ while frontier molecular orbital theory is a well established tool for rationalizing and predicting chemical reactivity. ${ }^{45}$ In 1990, Bader published a book that changed the mindsets of many chemists. In Bader's Atoms in Molecules theory, ${ }^{46}$ the chosen function is the one electron density $\rho(\mathrm{r})$, and the basins are associated with each of the atoms in the molecule. ${ }^{47}$ Electron density $\rho(\mathrm{r})$ rather than an orbital approach is a better choice for the description of chemical processes since it is a local function defined within the exact many body theory; moreover, it corresponds to an experimentally and accessible scalar field. Its paramount role in the description of many-body problems is supported by the Hohenberg-Kohn theorem (HKT), ${ }^{48}$ while density functional theory (DFT) ${ }^{48,49}$ asserts that the single particle density $\rho(\mathrm{r})$ contains all the information of a system, and the total energy attains the minimum value for the true density.

Conceptual DFT focuses on understanding chemical reactivity through various reactivity descriptors based on derivatives of $\rho(\mathrm{r})$ and its energy, such as electronegativity, hardness, and so on. ${ }^{50,51}$ These reactivity indices are well established concepts in the chemical language and help in the interpretation of chemical reactivity. But we need to recognize, as was recently remarked by Neese, ${ }^{52}$ that "a corollary is a statement commonly attributed to Max Planck that 'experiment is the only source of knowledge, the rest is poetry and imagination'. This candidly formulated sentence is, on one hand, a strong reminder to ground theory in experimental reality and, on the other hand, to carefully distinguish physical observables from unobservable quantities. The latter, for example molecular orbitals, various energy decomposition schemes, or reactivity indices, are 'interpretation aids'. They are of vital importance in creating a chemical language, guiding chemical thinking, and eventually inspiring new experiments. There is, however, no objective truth to these quantities, and it is largely a personal matter which interpretation aid provides the greatest inspiration to a given individual. However, physical observables have well-defined values and definitions that provide an unambiguous meeting point between theory and experiment".

One further step toward gaining a deeper insight into chemical reactivity is achieved by a successive detection of the electron density change throughout the course of a chemical reaction, in which continuous redistribution of $\rho(\mathrm{r})$ occurs, thereby providing valuable information about how and where the bond forming/breaking processes take place. Therefore, a chemical process cannot be understood in terms of just a simple redistribution of the atoms, but also as a dynamic process of evolution of the electron density along the reaction coordinate, where it is possible to identify 
changes in the electronic structure. In this sense, Solano-Altamirano and Hernández-Pérez have developed DensToolKit as a cross-platform suite for analyzing the molecular electron density $(\rho)$ and several fields derived from it, including the electron localization function (ELF). ${ }^{53}$

\section{Curly Arrow and Reaction Mechanism}

Every chemist is familiar with these drawings, which make this new selection rule very intuitive and accessible, while it bridges the gap between traditional reactivity theory and molecular electronics. In the essay entitled "Chemistry: A Panoply of Arrows", 54 Prof. Álvarez presents an overview on the historical use of arrows in chemistry highlighting the variety of meanings that a simple symbol such as an arrow may have. Their uses have varied over time: the alchemical symbols representing elements or compounds; in chemical equations to show the reversibility of a given chemical process; double-headed arrows to represent resonance structures or even tautomerism associated with the interconversion of two isomers through a simultaneous shift of a double bond and a proton; in orbital energy diagrams; in Jablonski diagrams indicating radioactive (straight arrows) and non-radioactive (wave arrows) transitions; in the stimulated emission of radiation that takes place in lasers; and up- and down-pointing arrows to depict the positive and negative spin of an electron, respectively. Very recently "bond" arrows have even been used to describe dative bonds in main-group compounds. ${ }^{55}$ Likewise, the description of chemical processes has been classically represented as sequences of elementary steps where transformations of formally double to simple bonds (or vice versa), electron pair rearrangements, and bond breaking/forming processes are clearly symbolized. The prototypical representation is provided by electron-pushing formalisms where the electron flow is represented with curved arrows. ${ }^{56}$ This type of representation for the electron flow movements is displayed to symbolize chemical reactivity in much of organic chemistry.

All these processes are still imagined and represented in chemistry textbooks that employ drawings involving curly arrows models. The history of curly arrows goes back about ninety years, when they were introduced in the seminal papers by Robinson and Ingold ${ }^{56-58}$. In general, the tails and heads of the curly arrows indicate chemical bonds that are weakened and strengthened due to loss or gain of valence electron density during the reaction, respectively, while the curve is not meant to describe a trajectory: it is only one way of connecting the departing and ending points of the electron displacement. In organic chemistry, transformations were simply represented by arrows that would result in an electron pair and atom placement consistent with the products in a meaningful way, providing mechanisms for transformations. Mechanistic reactions can be drawn as "arrow-pushing" diagrams ${ }^{59}$ showing the concerted electron movements. This representation appears to be a consequence of chemical intuition and is a fundamental part of the chemist's 
activity, although there is no experimental support for these curly arrows. In this sense, an elementary reaction can be associated with a single electron movement (e.g., radical reactions), movement of a single pair of electrons (e.g., simple addition or bond dissociation reactions), or the complex concerted movement of many electrons, e.g., $\mathrm{S}_{\mathrm{N}} 2$ or $\mathrm{S}_{\mathrm{N}} 1$ substitution, and pericyclic (Diels-Alder) reactions. For example, the usual reaction mechanism for these reactions that can be found in many organic chemistry textbooks is written as:

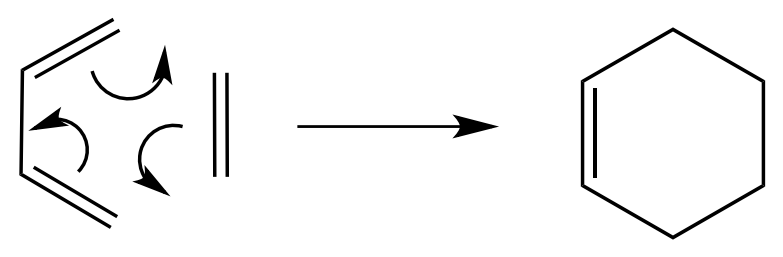

These curly arrows indicate how the bonds have to be rearranged in order to go from the reactants to the products. Generally speaking, there are many different possible ways to draw these arrows. These examples tend to explain the corresponding reaction mechanism, connecting the reactants to the reaction products, and it is associated with the electronic structure change during a chemical rearrangement. This concept is essential in chemical education as a fundamental tool enabling the comprehensive representation of the reaction mechanism associated with a chemical reaction. Interpretations of organic reactions by means of curly arrows ${ }^{60-62}$ are based on the classical concept of Lewis's electron pairs involved in individual chemical bonds. Many examples can also be found in textbooks on organic ${ }^{59,63-68}$, inorganic, ${ }^{69,70}$ and biochemistry. ${ }^{71,72}$ Therefore, organic, inorganic, and biochemists have developed and applied powerful albeit less quantitative rules for electronic redistributions which accompany the nuclear motions along the course of a given chemical rearrangement, although current textbooks on computational chemistry ${ }^{73,74}$ have exposed some flaws in the existing model of curly arrows. In this regard, Rzepa presented an instructive guide on the topic entitled "A curly-arrow pushing manual" (http://www.ch.imperial.ac.uk/rzepa/blog/?p=11741) in which some rules about the use of these mechanistic arrows are proposed, and complemented along some responses, even although arrowpushing is often regarded as far too approximate to be the matter of any rigorous definition. Likewise, Knizia and Klein ${ }^{75}$ very recently developed a procedure in which the bond rearrangements expressed by curly arrows can be directly observed from ab initio computations, as transformations of intrinsic bond orbitals along the reaction coordinate, although this important point warrants a more detailed discussion.

\section{Electron Flow}


The attempts made so far to extract the flow and electron transfer processes along the reaction pathway associated with a chemical reaction from quantum chemical calculations have been based either on wave function-based and orbital-based methods. These methods generate orbital representations of the wave-functions, and the derived based-energy properties that, in turn, assist the qualitative interpretation of chemical structure and reactivity. In this sense molecular orbitals make it possible to define a chemical bond, assigned to a pair of electrons shared by two or more nuclei, as put forward by Lewis. ${ }^{76}$ However, valence bond theory developed by Pauling, ${ }^{77-80}$ in which the superposition of resonating Lewis structures represents the chemical bonds of the molecule by localized electron pairs, provides an interpretation of the nature of bonds, the structure of the molecules, and even of their reactivity. ${ }^{81,82}$ As already stressed above, an elementary molecular process can be characterized by the flow of fundamental particles (i.e., electrons and nuclei) that compose the system. In consequence, the specific pathways of the particles constitute the mechanism of the process. The flow, in turn, is quantitatively described by the flux i.e., the time-sequence of maps of the rate of flow of electron density. For processes taking place in the electronic ground state, one typically employs the Born-Oppenheimer approximation and monitors the development of the electron density along the reaction pathway. The present example illustrates their potential for complex mechanisms and shows how theoretical and computational chemistry can directly establish reaction mechanisms in intuitive terms and in unprecedented detail. In consequence, there is a growing interest in explaining chemical reactivity arising from the redistribution of the electron density along the corresponding reaction pathway.

At the present time, a great deal of effort has been focused on characterizing and quantifying the electron flow in chemical processes. ${ }^{83-94}$ In this sense, it is now becoming possible to generate tunable, intense, ultrashort X-rays, ${ }^{95-97}$ electron pulses, ${ }^{98,} 99$ adding femtosecond temporal resolution to structural analysis. These pulses promise to provide time-resolved snapshots of physical, chemical, and biological processes in individual molecular systems; in other words these techniques allow the elementary steps involved in the chemical rearrangements to be characterized. Since chemical reactions involve ultrafast rearrangements of the valence electrons during the forming and breaking of chemical bonds, the necessity arises to monitor those electrons that dictate the course of chemical reactions. Thus, the remarkable properties of modern ultrashort X-ray and electron pulses seem to offer a considerable alternative in the domain of ultrafast electronic processes of molecular systems. In particular the degenerated Cope rearrangement of semibullvalene has been used as an example to illustrate the X-ray imaging of chemically active valence electrons during a pericyclic reaction. ${ }^{88}$ This approach makes it possible to extract changes in that part of the electron density directly related to bond making and bond breaking, namely, the chemical valence electron density from the overall X-ray scattering pattern - which is itself dominated by the core electrons - thereby 
allowing the imaging of the flow of valence electrons in space and time. Likewise, another important long-debated issue also addressed in this research concerns synchronous versus asynchronous bond breaking and forming processes in pericyclic reactions, although to date this debate had been mainly theoretical. According to recent quantum mechanical calculations and experiments for the Cope rearrangement of semibullvalene in the electronic ground state, the synchronicity of the process depends on the energy (temperature) of the reactant. ${ }^{93}$ Thus, synchronous bond forming and breaking (electron flow) is predicted for tunneling, which is dominant for pathways at low energies. In contrast, asynchronous electron flow has been predicted for the over-the-barrier pathway, typical of high excitation energies.

Other examples which represent the innovative progresses made in the characterization of the electron flow are the experimental visualization of the changes in molecular structures during both photochemical and thermal reactions. ${ }^{100-103}$ Indeed, the use of sub-5 fs pulse technology has allowed the direct observation of these molecular structural changes by real-time vibrational spectroscopy. This method makes it possible to analyze the time-dependent frequency shifts of certain vibrational molecular modes. While the quantification of the electron flux cannot be obtained from this technology, the characterization of the vibrational shifts can give a clear idea of those elementary steps that occur during a chemical transformation. In particular the Claisen rearrangement of allyl ethyl-, and allyl phenyl-ether have been studied by Iwakura et al. ${ }^{102-107}$ The determination of the elementary steps during those Claisen rearrangements by real-time vibrational spectroscopy suggests a detailed mechanism, which involves the pertinent breaking/forming processes in a corresponding reaction delay. Likewise, this research also reveals the asynchronous way of bond forming and bond breaking. However, it cannot offer any clues concerning the quantification of the electron flux in the reactive course.

\section{Quantum Chemical Topology}

The topology of the scalar fields associated with the electron density distribution is, in principle, independent of the approximations performed to calculate the approximate wave function. Theoretical studies on chemical reactivity are usually carried out within a Hilbert space, where the wave function is approximated by the set of molecular orbitals (canonical, NBO, or localized in one of an infinite number of ways), or are interpreted in terms of frontier orbital theory. ${ }^{45,108-111}$ In this context, bond breaking/forming processes can be studied by several tools such as bond orders, ${ }^{44}$ reaction force, ${ }^{112-116}$ and reaction electronic flux ${ }^{117-122}$ based on the use of reaction electronic flux derived from the conceptual density functional theory, together with a natural bond orbital analysis. Very recently, as mentioned earlier, Knizia et al. have presented the intrinsic bond orbitals that can 
be associated with a non-empirical form of localized molecular orbitals to obtain the electron flow for reaction mechanisms. ${ }^{75,123-125}$

On the other hand, topological analysis is a useful tool to characterize intra- and intermolecular interactions, and different types of bonding analysis methods are based on the topology of scalar fields, ${ }^{126}$ while different applications have already been published in the literature. ${ }^{127-133}$ Recently, different authors have answered the following questions: What is the significance of topological approach? Can new chemical concepts be found by a topological approach? What is the status of a chemical concept within a topological approach? Should topological approaches provide measurable quantities? Is it possible to predict the outcome of a topological approach without performing a calculation on a computer? What are new domains for which topological approaches would be useful $?^{134}$ Topological theory for chemical bond provides a linkage between the classical chemical bond representation derived from the Lewis theory and the first-principles quantum mechanical methods. Within this theory, a local function containing the chemical information is treated mathematically by partitioning the molecular space into subsystems (basins). ${ }^{135}$

The name 'quantum chemical topology"136, 137 has been introduced to embrace all topological investigations of three-dimensional scalar fields ${ }^{46,138-144}$ in order to rationalize the chemical bond and gain further understanding of the chemical reactivity. ${ }^{145-153}$ A number of excellent works on that subject have been published to highlight the importance of charge density analysis applied to chemical, biological systems, and solids. ${ }^{46,}$ 154-162 Very recently, Pendás and Hernández-Trujillo ${ }^{163}$ investigated the topology of a vector field, i.e., the Ehrenfest force density, which is the electrostatic force acting on any point in the electron density due to all the other particles in the molecule, while Dillen ${ }^{164}$ has analyzed the topology of the Ehrenfest force density using basis sets based on Slater-type orbitals. In this context, the best known approaches are the "atoms in molecules" theory (QTAIM), which relies on the properties of the empirically observable electron density $\rho(\mathrm{r})^{46,156,159,165}$ and the ELF methods. ${ }^{166}$ This was emphasized by the founder of QTAIM, Richard Bader, who stated, "further study of the gradient vector field of the electron density leads to a complete theory of structure and structural stability". ${ }^{167}$ The QTAIM has been widely used to study molecules, ${ }^{168,} 169$ solids, ${ }^{170-172}$ complexes, ${ }^{173-176}$, and chemical reactions. ${ }^{177-179}$ Although electron density in principle contains all the chemical information about the corresponding molecule, it does not give a clear picture of the electron distribution. Therefore, it is often preferable to partition such total electron density into different regions, which can be viewed as the more conventional chemical bonds, lone pairs, etc. For this purpose and using the topology of the electron density, the atoms inside a molecule are defined by regions in space called atomic basins, which are bounded by zero-flux surfaces. Atomic properties (e.g., electron population and 
atomic volume) are calculated using the volume integral of the appropriate variable over the atomic basin. ELF was introduced by Becke and Edgecombe ${ }^{166}$ for Hartree-Fock theory and extended to Kohn-Sham DFT via an alternative interpretation put forward by Savin and Silvi, ${ }^{144}$ and has enjoyed enormous success as a tool for understanding and visualizing chemical bonds. This analysis is based on the topology of the ELF. ${ }^{166,180-182}$

The ELF has been originally designed by Becke and Edgecombe to identify "localized electronic groups in atomic and molecular systems". ${ }^{166}$ Many interpretations of ELF have been given so far in order to get expressions beyond the HF approximation or to provide relationships with other theoretical tools. Savin et al. have demonstrated that the ELF formula can be extended to DFT and Kohn-Sham orbitals, and in this case, the physical meaning of the ELF kernel is that of a local excess of kinetic energy density for the actual system and the respect to a jellium of same density. ${ }^{183}$ Orbital-based interpretations of ELF have been proposed by Burdett ${ }^{184}$ and Nalewajski et al. ${ }^{185}$ who studied the non-additive inter-orbital Fisher information. Another route pioneered by Dobson ${ }^{186}$ explicitly explored the pair functions. This route has been developed independently by Kohout et al. with the Electron Localization Indicator (ELI) ${ }^{187,188}$ and by one of us, ${ }^{189}$ with the spin pair composition, $\mathrm{c} \pi(\mathrm{r})$, in order to generalize ELF to correlated wave functions. ${ }^{190,}{ }^{191}$ The partition of the molecular space provided by the ELF gradient field yield non-overlapping volumes which minimize the variance of its population with respect to the variation of their boundaries. ${ }^{192}$ This assumption is supported by numerical experiments on atoms ${ }^{192}$ and hydrogen bonded complexes ${ }^{193}$ as well as by theoretical arguments. ${ }^{194}$ It is therefore widely used to characterize localized electrons. ELF basins are related to pairs or groups of electrons, such as core and valence basins. Lone pairs and bonds involving hydrogen atoms are associated with monosynaptic basins, whereas covalent and polar bonds usually exhibit disynaptic basins. ${ }^{192,} 195$ The electron population and the shape of the ELF basins are commonly used to feature bond interactions. ${ }^{144,196}$ A topological analysis allows for an evaluation of the relationship between the nature of the bond and the chemical reactivity of the molecule, while the quantification of electron density and the associated energetics in both intraand intermolecular space in solids is thus of extreme interest. Very recently, some of us have revisited the ELF approach to chemical bonding as a tool to check the reliability of the Lewis hypotheses. ${ }^{197}$

Nine years ago, we showed that the formation or dissociation of diatomic molecules is not accompanied by any change in the topology of the electron density. ${ }^{198}$ To overcome this drawback, the changes in the structure throughout the progress of a bond making/forming process can be achieved by analyzing the topology of the Laplacian of $\rho(r)$. This strategy has been used by CortésGuzman et al., ${ }^{199}$ based on the valence shell charge concentration, ${ }^{200}$ to describe the changes in electron density concentrations and depletions around the bonding area of an atom. In addition, 
Quirante et al. ${ }^{201}$ followed the evolution of the topology of the Laplacian of the electronic charge density and its gradient vector field for rationalizing the catalytic activity of copper in the cycloaddition of azide and alkynes.

\section{Bonding Evolution Theory}

The analysis of the electronic structure, at the corresponding stationary points of the PESs, represents the most frequent and relevant application of modern computational chemistry. Although the accuracy of the prediction of molecular structures, energies, and physical observables is not always guaranteed, the description of chemical processes has been carried out to a great extent using quantitative concepts derived from first-principle calculations. In this sense, interpretative tools are necessary to retrieve chemical structure reactivity, and more specifically to understand the process of bond formation and bond breaking during chemical reactions. Although the $\mathrm{HKT}^{48}$ guarantees that all the molecular information is encoded in the electron density, the physical description of chemical systems requires additional postulates to extract observable information in terms of atomic contributions. In this sense, Bader's QTAIM has taken charge of this matter by introducing a mathematical framework that is able to correlate the physical behavior of the molecular electron density with its atomic contributions. Thus, concepts such as bond path allow the evolution of a certain interaction between/among atoms to be monitored in the course of a chemical transformation and, consequently, a given chemical system can be described in terms of the redistribution of the electron density in the course of the reaction pathway connecting the stationary points of the PES. Bader and coworkers pioneered the study of the structural changes of the electron density using Thom's theory of elementary catastrophes (CT), ${ }^{202}$ although the applicability of QTAIM to reaction mechanisms is limited to intramolecular processes since there are no topological changes in the charge density gradient field when a diatom dissociates. Bader's methodology has been further revised by Krokidis and Silvi, who implemented the bonding evolution theory (BET), ${ }^{203}$ which combines Thom's catastrophe theory ${ }^{204}$ and the topological analysis of ELF. Thus, the topological analysis of the $\mathrm{ELF}^{144,166,180}$ is becoming increasingly popular in the characterization of chemical bonding in systems ranging from clusters in the gas phase to solids.

The topological partition of the ELF gradient field provides a basin of attractors, which are classified as core and valence basins. Core basins C(A) can be thought of atomic cores, while valence basins $\mathrm{V}(\mathrm{A})$ can be interpreted as bond and lone pairs, where $\mathrm{A}$ is the atomic symbol of the element. $\mathrm{V}(\mathrm{A}), \mathrm{V}(\mathrm{A}, \mathrm{B})$ or $\mathrm{V}(\mathrm{A}, \mathrm{B}, \mathrm{C})$ are characterized by their coordination number with core

basins (synaptic order) ${ }^{205}$ as monosynaptic, disynaptic or trisynaptic basins, respectively. A quantitative analysis is further achieved by integrating the electron density and the pair functions 
over the volume of the basin, yielding basin populations. Consequently, this description recovers the Lewis bonding model to suggest a graphical representation of the molecular system that makes it possible to describe how the connectivity among atoms evolves in a chemical rearrangement. Thus, according to the theory of dynamic systems, it can be considered structurally stable if a small perturbation is only possible for values of the control parameters in well-defined ranges, namely, structural stability domains (SSDs), where all of the critical points are hyperbolic and separated by catastrophic points at which at least one critical point is non-hyperbolic. Therefore, during a chemical rearrangement, the chemical system goes from a given SSD to another by means of bifurcation catastrophes occurring at the turning points (TPs). These TPs are identified according to Thom's classification. ${ }^{206}$ In this way, a chemical reaction is viewed as a sequence of elementary chemical processes characterized by a catastrophe. These chemical processes are classified according to the variation of the number of basins $\mu$ and/or of the synaptic order $\sigma$ of at least one basin. Thom's classification in chemical reactions has been described in detail elsewhere. ${ }^{148}$ Several research groups have used the electron density, ${ }^{207-212}$ its laplacian, ${ }^{213} \mathrm{ELF},{ }^{148,214-216}$ to study a wide range of reaction mechanisms. ${ }^{148,198,214-230}$ This combined method that we use herein has previously been described in great detail to establish electron density redistribution in the course of structural rearrangements. ${ }^{177,198,218,231}$ On the other hand, Silvi et al. ${ }^{232}$ have developed a cross ELF/noncovalent interaction (NCI) analysis to offer an alternative look at chemical mechanisms for prototypical organic reactions, while a combination of QTAIM and the NCI index has been employed to describe the molecular mechanism for the $\mathrm{NH}_{3}+\mathrm{LiH} \rightarrow \mathrm{LiNH}_{2}+\mathrm{H}_{2}$ reaction. ${ }^{233}$ Very recently, BET has been coupled with the quantum mechanics/molecular mechanics (QM/MM) method in order to study biochemical reaction paths. The evolution of the bond breaking/forming processes and electron pair rearrangements in an inhomogeneous dynamic environment provided by the enzyme has been elucidated, ${ }^{234}$ while Piquemal et al. ${ }^{235}$ have coupled ELF/NCI analysis for enzyme reactions.http://pubs.rsc.org/is/content/articlehtml/2015/cp/c5cp05518k - cit59

In sum, BET analysis enables us to describe and understand the reaction mechanism. BET studies are capable of enabling explanations and predictions for chemical reactions and classical concepts, such as Rice and Teller principle, the Hammond postulate, as well as the reciprocal VSEPR approach ${ }^{197,236-240}$

\section{Curly Arrows naturally arise from the BET Analysis}

In the search for a general physical grounding capable of accounting for a quantum representation of the arrows in Lewis structures, here we shall go beyond the energetic description of chemical processes. Although most current research is focused on the accurate prediction of energy barriers and reaction energies of chemical reactions, an understanding of their origin based 
on the electron density is desirable. In this sense, we have sought to identify how the electronic flow in a molecule proceeds as a function of reaction progress considering the scalar field of the ELF, giving as a result the qualitative graphical representation of curly arrows that is so common in organic chemistry. Thus, the characterization and identification of chemical events like the weakening or strengthening of chemical bonds, forming/breaking processes, as well as rearrangements or formation/annihilation of pairs of electrons along the reaction coordinate obtained from the BET procedure gives rise to the natural appearance of curly arrows when the evolution of the population of ELF-basins is analyzed. In consequence, this procedure allows a very simple description of how the electron density is redistributed in chemical rearrangements and, in turn, it retrieves the appearance of curly arrows used to describe chemical processes. Technically, the way to proceed with the BET analysis basically consists in the respective characterization of the intrinsic reaction coordinate (IRC) path in order to connect the corresponding stationary points on the PES. Subsequently, at each point on the IRC path a full ELF topological analysis is performed, allowing an electronic molecular description of the system in the course of the reaction, where different kinds of ELF attractors are characterized and integrated to obtain their respective populations. This approach can adequately describe the thermal degenerated Cope rearrangement (DCR) of semibullvalene (SBV), ${ }^{241}$ showing the order, direction, and asynchronicity of the valence electron density rearrangement in the course of this chemical process. The rationale for of this study essentially arises from the results of previous works concerning asynchronous electronic fluxes that accompany the breaking and making of covalent bonds during the DCR of SBV. ${ }^{88,93,94,242}$ Figure 1 depicts five different SSDs associated with the corresponding chemical events involved in the DCR of SBV. The energy barrier of the process was calculated to be $4.5 \mathrm{kcal} \mathrm{mol}^{-1}$, in good agreement with previous studies. ${ }^{243}$ Likewise, the evolution of the ELF-basins in the course of the reaction predicts an early breaking of the C2-C8 bond. In terms of the ELF topology, it is reflected in an evident reduction in the population of the disynaptic basin $\mathrm{V}(\mathrm{C} 2, \mathrm{C} 8)$. Likewise, an increment in the population of the disynaptic basin $\mathrm{V}(\mathrm{C} 2, \mathrm{C} 3)$ and a reduction in the population of the disynaptic basin $\mathrm{V}(\mathrm{C} 3, \mathrm{C} 4)$ reveals a simultaneous change in the bond order (from single to double and vice versa). Note that due to the symmetry of the SBV the same behavior is observed for the respective disynaptic basins $\mathrm{V}(\mathrm{C} 7, \mathrm{C} 8)$ and $\mathrm{V}(\mathrm{C} 6, \mathrm{C} 7)$. When the system reaches the TS zone, a slight increase in the population of the disynaptic basin $\mathrm{V}(\mathrm{C} 1, \mathrm{C} 8)$ and $\mathrm{V}(\mathrm{C} 1, \mathrm{C} 2)$ is also observed, thereby indicating that the valence electron density is distributed in the ring formed by the cyclic carbon skeleton C1-C2-C3-C4-C5-C6-C7-C8. Interestingly, the population of the disynaptic basin $\mathrm{V}(\mathrm{C} 1, \mathrm{C} 5)$ remains practically unaltered in the course of the process, thus demonstrating that there are no electron density flows in the region between $\mathrm{C} 1$ and $\mathrm{C} 5$ atoms. After the system surpasses the TS, the population of the disynaptic basin $\mathrm{V}(\mathrm{C} 2, \mathrm{C} 3)$ increases considerably, while part of the 
electron density is predicted to be concentrated in the region of the $\mathrm{C} 4$ and $\mathrm{C} 6$ atoms, giving rise to the formation of the monosynaptic basins $V(C 4)$ and V(C6). Subsequently, the appearance of the disynaptic basin $\mathrm{V}(\mathrm{C} 4, \mathrm{C} 6)$ at the late stage of the process accounts for the formation of the C4-C6 bond. Interestingly, the breaking/forming processes of $\mathrm{C} 2-\mathrm{C} 8$ and $\mathrm{C} 4-\mathrm{C} 6$ (strictly from the ELFtopological point of view) neither take place at the TS structure nor occur simultaneously. Thus, the ELF topological description accounts for the asynchronicity of the electron density flow in the course of thermal ring aperture. This behavior is predicted in good agreement with previous studies. ${ }^{88,93,94,242}$ According to the above findings, the reaction mechanism can be illustrated as depicted in Scheme 1, where the evolution of the basin population in every SSD accounts for the curly arrows which stand for the electron density flow. From this analysis, we can conclude that this thermal rearrangement proceeds basically in three consecutive stages: (a) $\mathrm{C} 2-\mathrm{C} 8$ bond-breaking process; (b) reduction of double bonds $\mathrm{C} 3=\mathrm{C} 4$ and $\mathrm{C} 6=\mathrm{C} 7$ to single ones and transformation of single bonds $\mathrm{C} 2-\mathrm{C} 3$ and $\mathrm{C} 7-\mathrm{C} 8$ into double ones; and (c) C4-C6 bond-forming process.

Yet, the reorganization of electron density under the framework of BET corresponding to the thermal ring apertures for the cyclobutene and cyclohexa-1,3-diene giving rise to 1,3 butadiene and (Z)-hexa-1,3,5-triene, respectively, have also been studied in detail. ${ }^{218}$ In particular, for the ring aperture in cyclobutene, the process is predicted to be exothermic by $12.0 \mathrm{kcal} \mathrm{mol}^{-1}$ and associated with an energy barrier of $35.6 \mathrm{kcal} \mathrm{mol}^{-1}$. The full ELF-topological analysis predicts five different SSDs for the process (see Figure 2). The topological description is described in detail elsewhere. ${ }^{218}$ The evolution of the basin population in the course of the ring aperture first reveals a weakening in C3-C4 bond: the disynaptic basin $\mathrm{V}(\mathrm{C} 3, \mathrm{C} 4)$ is divided into two monosynaptic basins $\mathrm{V}(\mathrm{C} 3)$ and $\mathrm{V}(\mathrm{C} 4)$. The rupture of the C3-C4 bond - in terms of the ELF-topological description - also gives rise to a slight increment in the population of the disynaptic basins $\mathrm{V}(\mathrm{C} 2, \mathrm{C} 3)$ and $\mathrm{V}(\mathrm{C} 1, \mathrm{C} 4)$. Likewise, the reduction in the populations of the disynaptic basins $\mathrm{V}_{\mathrm{i}=1,2}(\mathrm{C} 1, \mathrm{C} 2)$ and their subsequent transformation into single disynaptic basins $\mathrm{V}(\mathrm{C} 1, \mathrm{C} 2)$ prior to the TS reveals the change in the order of the $\mathrm{C} 1-\mathrm{C} 2$ bond, from double to single. In the TS, the annihilation of the monosynaptic basins $\mathrm{V}(\mathrm{C} 3)$ and $\mathrm{V}(\mathrm{C} 4)$ accounts for the vanishing of the electron density in the region between the $\mathrm{C} 3$ and $\mathrm{C} 4$ atoms. Then, a gradual accumulation of electron density in the region of the disynaptic basins $\mathrm{V}(\mathrm{C} 1, \mathrm{C} 4)$ and $\mathrm{V}(\mathrm{C} 2, \mathrm{C} 3)$ entails a change in the order of these two bonds from single to double, which is clearly evidenced by the transformation into two disynaptic basins $\mathrm{V}_{\mathrm{i}=1,2}(\mathrm{C} 1, \mathrm{C} 4)$ and $\mathrm{V}_{\mathrm{i}=1,2}(\mathrm{C} 2, \mathrm{C} 3)$, respectively. Hence, the single-step mechanism for the thermal ring aperture under the framework of the BET reveals, first, the breaking process of the C3-C4 bond, then the reduction of the double bond $\mathrm{C} 1=\mathrm{C} 2$ to single $\mathrm{C} 1-\mathrm{C} 2$, and lastly the transformation of the single bonds $\mathrm{C} 1-\mathrm{C} 4$ and $\mathrm{C} 2-\mathrm{C} 3$ into double ones. In consequence, the electron density redistribution in the course of the thermal ring aperture can be simply depicted according to Scheme 2 by just 
following the evolution of the population of basins for each SSD obtained in the framework of the BET analysis.

Additionally, the activation energy for the thermal ring aperture of the cyclohexa-1,3-diene is predicted to be $45.0 \mathrm{kcal} \mathrm{mol}^{-1}$, which is considerably higher in energy than the thermal ring aperture for cyclobutene; likewise, the process is calculated to be endothermic by $25 \mathrm{kcal} \mathrm{mol}^{-1}$ (see Figure 3). The global process involves the breaking of the C5-C6 bond with concomitant transformation of the double bonds $\mathrm{C} 1=\mathrm{C} 2$ and $\mathrm{C} 3=\mathrm{C} 4$ into single ones, and the transformation of the single bonds C1-C6, C2-C3, and C4-C5 into double ones. The full ELF-topological analysis describes this chemical rearrangement in six different SSDs. The BET monitoring first predicts the simultaneous transformation of the double bonds $\mathrm{C} 1=\mathrm{C} 2$ and $\mathrm{C} 3=\mathrm{C} 4$ into single ones. This is reflected in the gradual reduction of the basin population of the disynaptic basins $\mathrm{V}_{\mathrm{i}=1,2}(\mathrm{C} 1, \mathrm{C} 2)$ and $\mathrm{V}_{\mathrm{i}=1,2}(\mathrm{C} 3, \mathrm{C} 4)$ and their subsequent merging into the single disynaptic basins $\mathrm{V}(\mathrm{C} 1, \mathrm{C} 2)$ and $\mathrm{V}(\mathrm{C} 3, \mathrm{C} 4)$, respectively. The weakening of the basin population of the disynaptic basin $\mathrm{V}(\mathrm{C} 5, \mathrm{C} 6)$ then brings about its division into two non-bonding monosynaptic basins $\mathrm{V}(\mathrm{C} 5)$ and $\mathrm{V}(\mathrm{C} 6)$. Before the system reaches the TS a pronounced reduction in the monosynaptic basins V(C5) and V(C6) brings about their corresponding annihilation, thus promoting the delocalization of the electron density over the whole carbon skeleton. After the system surpasses the TS zone, an increment in the population of the disynaptic basins $\mathrm{V}(\mathrm{C} 1, \mathrm{C} 6)$ and $\mathrm{V}(\mathrm{C} 4, \mathrm{C} 5)$ causes it to split into two disynaptic basins $\mathrm{V}_{\mathrm{i}=1,2}(\mathrm{C} 1, \mathrm{C} 6)$ and $\mathrm{V}_{\mathrm{i}=1,2}(\mathrm{C} 4, \mathrm{C} 5)$ accounting for the formation of the double bonds $\mathrm{C} 1=\mathrm{C} 6$ and $\mathrm{C} 4=\mathrm{C} 5$, respectively. Then, in a later stage of the process an accumulation in the electron density in the disynaptic basin $\mathrm{V}(\mathrm{C} 2, \mathrm{C} 3)$ causes it to split into two disynaptic basins $\mathrm{V}_{\mathrm{i}=1,2}(\mathrm{C} 2, \mathrm{C} 3)$ leading to the formation of the double bond $\mathrm{C} 2=\mathrm{C} 3$. The $\mathrm{BET}$ analysis shows a primary reduction of the double bonds $\mathrm{C} 1=\mathrm{C} 2$ and $\mathrm{C} 3=\mathrm{C} 4$ to single ones. Second, the breaking process of the $\mathrm{C} 5-\mathrm{C} 6$ bond takes place, giving rise to a redistribution of the electron density along the carbon skeleton. Once the system surpasses the TS, the electron density is redistributed resulting in the formation of the double bonds $\mathrm{C} 1=\mathrm{C} 6$ and $\mathrm{C} 4=\mathrm{C} 5$ and, lastly, the formation of the double bond $\mathrm{C} 2=\mathrm{C} 3$. The evolution of the basin population results in the schematic representation of the curly arrows depicted in Scheme 3. Note that in both thermal ring apertures, the processes correspond to asynchronous electron density rearrangements.

The last example analyzed concerns the reaction mechanism of the ring closure process in (3Z,5Z)-octa-1,3,5,7-tetraene to yield (1Z,3Z,5Z)-cycloocta-1,3,5-triene. ${ }^{222}$ Nevertheless, for the sake of clarity, here this process will be analyzed in a reverse way in order to compare this chemical rearrangement with the previous ring aperture cases (see Figure 4). The process represents complex and coupled rearrangements of both formal single and double carbon-carbon chemical bonds. The global process involves the formation of one single carbon-carbon bond C7-C8, a transformation of 
three double bonds $\mathrm{C} 1=\mathrm{C} 2, \mathrm{C} 3=\mathrm{C} 4, \mathrm{C} 5=\mathrm{C} 6$ into single ones, and transformation of four single bonds $\mathrm{C} 1-\mathrm{C} 8, \mathrm{C} 2-\mathrm{C} 3, \mathrm{C} 4-\mathrm{C} 5$, and $\mathrm{C} 6-\mathrm{C} 7$ into double ones. The ring aperture takes place via a onestep mechanism and is calculated to be endothermic by $19.6 \mathrm{kcal} \mathrm{mol}^{-1}$, while its activation energy barrier is predicted to be $22.1 \mathrm{kcal} \mathrm{mol}^{-1}$. The BET analysis along the IRC path reveals six SSDs distributed throughout the thermal process (see Figure 4). The first change reported by the ELFtopological analysis corresponds to the weakening of the single bond C7-C8. It is reflected by a reduction in the population of the disynaptic basin $\mathrm{V}(\mathrm{C} 7, \mathrm{C} 8)$ in the early stage of the process, bringing about the division into two monosynaptic basins $\mathrm{V}(\mathrm{C} 7)$ and $\mathrm{V}(\mathrm{C} 8)$. This indicates that the first event in the thermal ring aperture corresponds to the breaking process of the single bond C7C8. Then, the merging of the disynaptic basins $\mathrm{V}_{\mathrm{i}=1,2}(\mathrm{C} 1, \mathrm{C} 2), \mathrm{V}_{\mathrm{i}=1,2}(\mathrm{C} 3, \mathrm{C} 4)$, and $\mathrm{V}_{\mathrm{i}=1,2}(\mathrm{C} 5, \mathrm{C} 6)$ into single ones accounts for the reduction of the double bonds to single bonds $\mathrm{C} 1-\mathrm{C} 2, \mathrm{C} 3-\mathrm{C} 4$, and $\mathrm{C} 5$ C6. Likewise, a slight increment in the population of the disynaptic basins $\mathrm{V}(\mathrm{C} 2, \mathrm{C} 3)$ and $\mathrm{V}(\mathrm{C} 4, \mathrm{C} 5)$ is observed. Prior to the TS, the residual electron density (which belongs to the non-bonding monosynaptic basins $\mathrm{V}(\mathrm{C} 7)$ and $\mathrm{V}(\mathrm{C} 8)$ ) in the region between the $\mathrm{C} 7$ and $\mathrm{C} 8$ atoms is continuously transferred to the contiguous disynaptic basins $\mathrm{V}(\mathrm{C} 1, \mathrm{C} 8)$ and $\mathrm{V}(\mathrm{C} 6, \mathrm{C} 7)$, bringing about the annihilation of these two monosynaptic basins. This topological change promotes the delocalization of the electron density over the carbon skeleton. After the systems surpass the TS, the disynaptic basins $\mathrm{V}(\mathrm{C} 1, \mathrm{C} 8)$ and $\mathrm{V}(\mathrm{C} 6, \mathrm{C} 7)$ are divided into two basins $\mathrm{V}_{\mathrm{i}=1,2}(\mathrm{C} 1, \mathrm{C} 8)$ and $\mathrm{V}_{\mathrm{i}=1,2}(\mathrm{C} 6, \mathrm{C} 7)$ due to a considerable increment in their populations, thus indicating the transformation of the single bond C1-C8 and C6-C7 into double ones. Finally, the last ELF topological change accounts for the transformation of the single bonds $\mathrm{C} 2-\mathrm{C} 3$ and $\mathrm{C} 4-\mathrm{C} 5$ into double bonds $\mathrm{C} 2=\mathrm{C} 3$ and $\mathrm{C} 4=\mathrm{C} 5$. In the last stage of the process, a specific concentration of electron density in the basins $\mathrm{V}(\mathrm{C} 2, \mathrm{C} 3)$ and $\mathrm{V}(\mathrm{C} 4, \mathrm{C} 5)$ triggers a division into two disynaptic basins $\mathrm{V}_{\mathrm{i}=1,2}(\mathrm{C} 2, \mathrm{C} 3)$ and $\mathrm{V}_{\mathrm{i}=1,2}(\mathrm{C} 4, \mathrm{C} 5)$, giving rise to the formation of $(1 \mathrm{Z}, 3 \mathrm{Z}, 5 \mathrm{Z})$-cycloocta-1,3,5-triene. A representation of all these chemical events is summarized in Scheme 4, where the appearance of curly arrows naturally arises following the evolution of the basin population in the course of the chemical rearrangement. The scheme accounts primarily for the breaking process of the C7-C8 bond. Secondly, the reduction of the double bonds $\mathrm{C} 1=\mathrm{C} 2, \mathrm{C} 3=\mathrm{C} 4$, and $\mathrm{C} 5=\mathrm{C} 6$ to single ones takes place bringing about a redistribution of the electron density in the carbon skeleton. Finally, the single bonds C1-C8, C6-7, C2-C3, and C4-C5 are transformed into double ones.

\section{Conclusions}

One of the most fundamental concepts within chemistry, i.e., the chemical bond, is still a matter of lively debate among chemists and physicists. The nature of chemical bonds is still ambiguous and the lack of a unique and precise definition makes this concept very controversial. In 
the above context, new and more robust models of chemical bonds (structure) and chemical reactivity are necessary to further our understanding of chemical phenomena. Probing the electron density distribution during a chemical reaction can provide important insights, making it possible to understand and control chemical reactions.

Understanding chemical structure and unraveling reactivity patterns, i.e., mechanisms that govern the making and breaking of bonds in terms of the electron density distribution and their changes along the reaction pathway, is a major goal of chemistry. Electron density distribution is an observable and therefore it can also be determined experimentally. ${ }^{155}$ This representation can be considered as a step ahead with respect to the interpretation based on the concept of molecular orbitals (MOs) ${ }^{75,244}$ or the valence bond theory (VB), ${ }^{245}$ or reactivity indices derived from conceptual DFT. ${ }^{50,51}$ Actually, the current electronic structure theory of molecules, i.e., quantum chemistry, can provide the accurate snapshots of electronic distribution associated with geometrical changes of even very large molecules. Although the HKT guarantees that all the molecular information is encoded in the electron density, the physical description of chemical systems requires additional postulates for extracting observable information in terms of atomic contributions. The combination of the ELF and Thom's catastrophe theory has been consolidated as a powerful tool to analyze the course of a given chemical rearrangement, and allows us to identify how electronic flow in a molecule occurs as a function of reaction progress, which constitutes the motivation of the present work. In the present study, we have used the ELF and CT to analyze and monitor the progress of chemical events, that is, bond breaking/forming process, lone pair rearrangements, and so forth, throughout a given reaction mechanism. However, a direct relationship between concepts such as curly arrows, aromaticity, and electron redistribution patterns along a given reaction pathway is not trivial. To properly justify any such connection, it is necessary to employ a theoretical framework that directly relates the experimental observable with the hypothesis being investigated. Taking into account this theoretical background, our results intend to clarify the evolution of atomic interactions. Furthermore, curly arrows can be based on physical grounds and show how BET can directly afford fresh and richer insights and more correct descriptions of reaction mechanisms in intuitive terms and in unprecedented detail.

The development of BET, as a quantum mechanical treatment of chemical structure and reactivity, provides an understanding based on the analysis of ELF topology and the CT of electron flow as the reaction proceeds. The authors apologize to the reader for the often intentional but sometimes unintentional simplification of the presentation. The purpose of this work is to demonstrate the need to allow a degree of chemical complexity to enter into the rigorous world of structure and chemical reactivity. This work should show that bringing together electron flow and the reaction mechanism is a central paradigm in quantum mechanics to unify concepts in chemical 
reactivity. We think that this work brings concepts of two worlds of chemistry together (curly arrows and electron flow from BET) through the formulation of a practical scheme to represent the reaction mechanism of a given chemical rearrangement on a quantum mechanics framework. The BET method allows us to search for the degree of fitness of the Lewis hypothesis of chemical bonding as an electron pairing phenomenon, while acquiring a quantum chemical support. On this basis, we should be able to predict quantitatively the reaction mechanics and outcome of the physical processes that lead from reactants to products via the corresponding transition structure and possible intermediates.

With respect to other quantum chemical techniques, which explain the reactivity from the electronic structures of the reactants and of the transition state at given static geometries, BET considers the classical nuclear trajectories as the driving force of the electronic rearrangements occurring along the reaction pathway. It is therefore consistent with the DFT, in which the chemistry is contained in the external potential, in other words the nuclear potential. In a thermal chemical reaction, the conversion of translational kinetic energy into vibrational energy due to the inelastic collisions of the molecules induce excitations of the vibrational modes which promote the system to the transition state. The deformation of the nuclear geometry is at the origin of a stress of the electron density, which undergoes rearrangements under relaxation. The BET quantitatively describes these rearrangements, which can be qualitatively predicted by the reciprocal VSEPR rules. $^{237}$

Our long-term objective is to improve our ability to predict chemical reactivity using BET, and here we have shown how this end is achieved without performing (often costly) high-level energy calculations. We believe that this kind of study may serve to provide more specific information with which to nourish chemical reactivity theories. Furthermore, it is also our contention that these observations might be amenable to experimental verification through selective laser pulses, and monitoring the electronic fluxes that accompany the breaking and making of chemical bonds during chemical rearrangements.

In sum, we try to study chemical structure and reactivity from the strict point of view of quantum mechanics and, by extension, of quantum chemistry. Such a situation is clearly defined by using BET. We hope that these examples demonstrate the power of relatively simple ideas applied to understanding chemical structure and reactivity. 


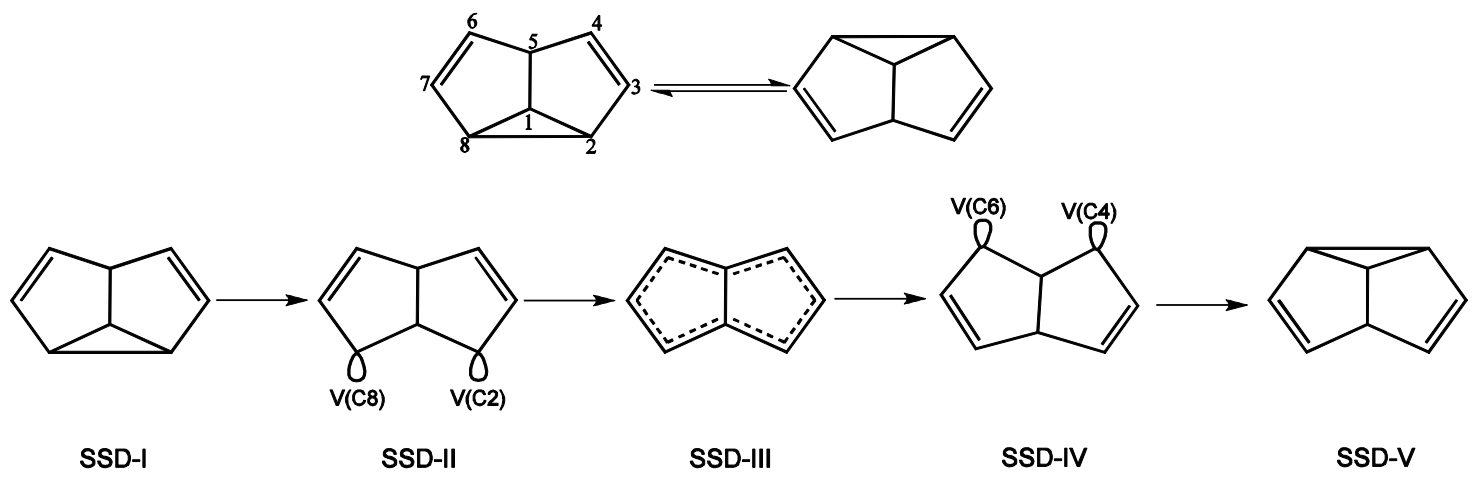

Figure 1. Thermal degenerated Cope rearrangement of semibullvalene and the corresponding representation of the SSDs from the perspective of the ELF analysis calculated at the DFT level of calculation. Full lines and ellipses represent disynaptic and monosynaptic basins. Dashed lines indicate a large basin population.

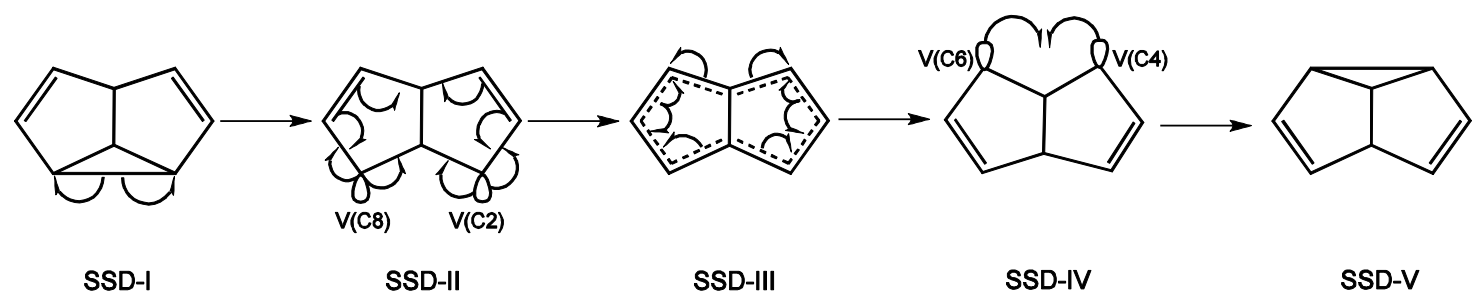

Scheme 1

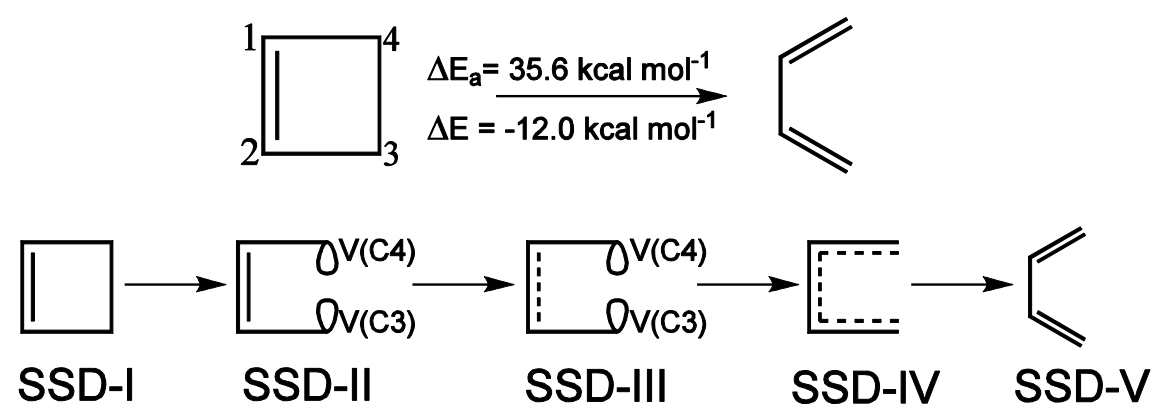

Figure 2. Thermal ring aperture for cyclobutene to 1,3-butadiene and the corresponding representation of the SSDs from the perspective of the ELF analysis calculated at the DFT level of calculation. Full lines and ellipses represent disynaptic and monosynaptic basins. Dashed lines indicate a large basin population.

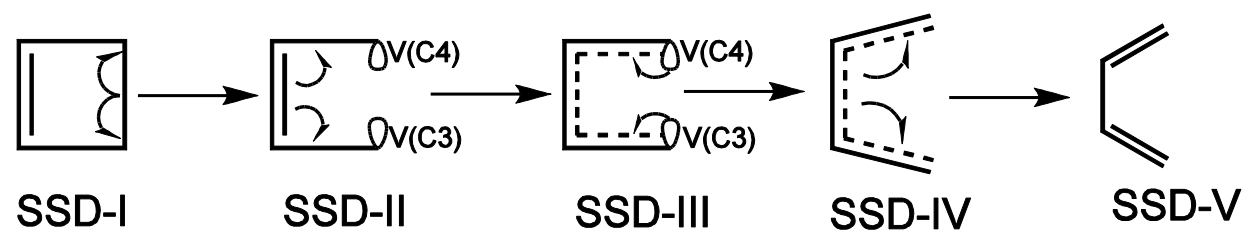


Scheme 2
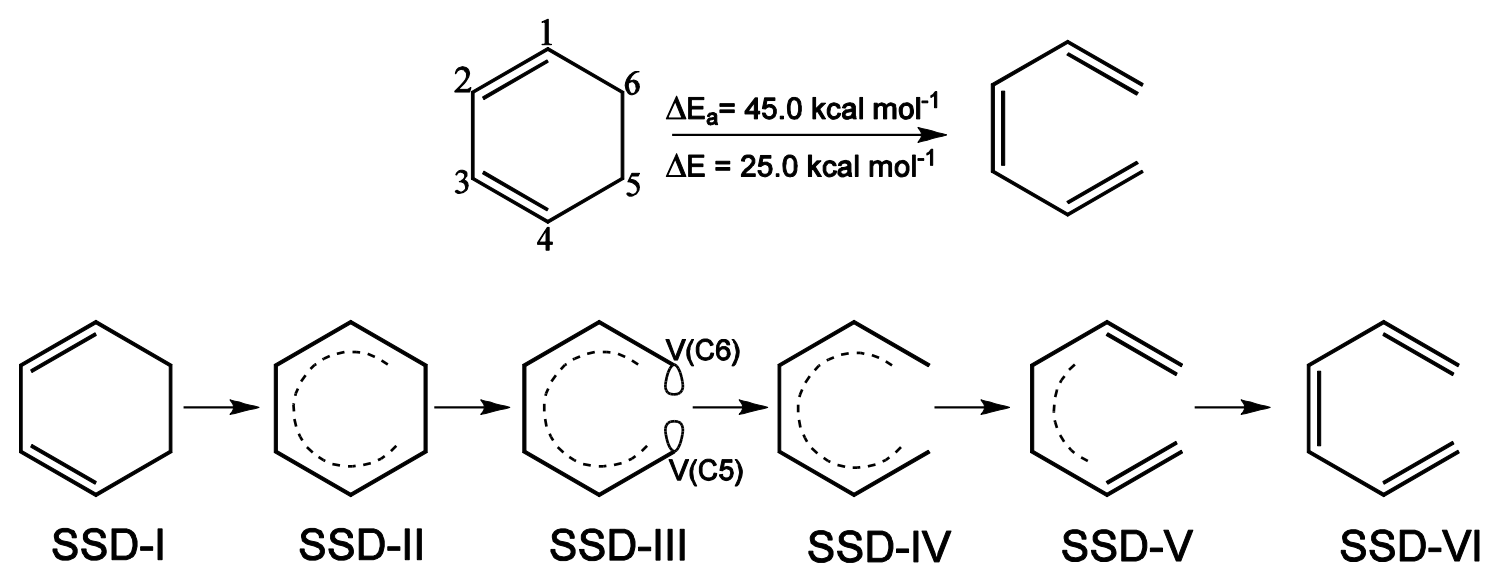

Figure 3. Thermal ring aperture for cyclohexa-1,3-diene to (Z)-hexa-1,3,5-triene and the corresponding representation of the SSDs from the perspective of the ELF analysis calculated at the DFT level of calculation. Full lines and ellipses represent disynaptic and monosynaptic basins. Dashed lines indicate a large basin population.

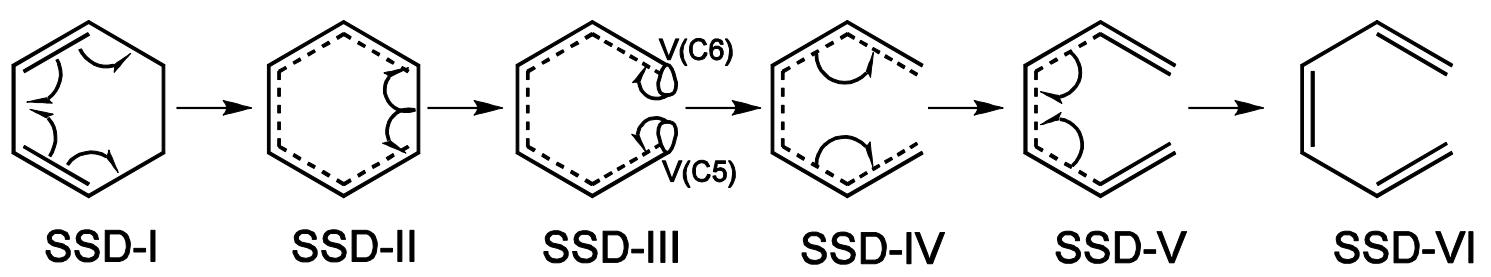

Scheme 3
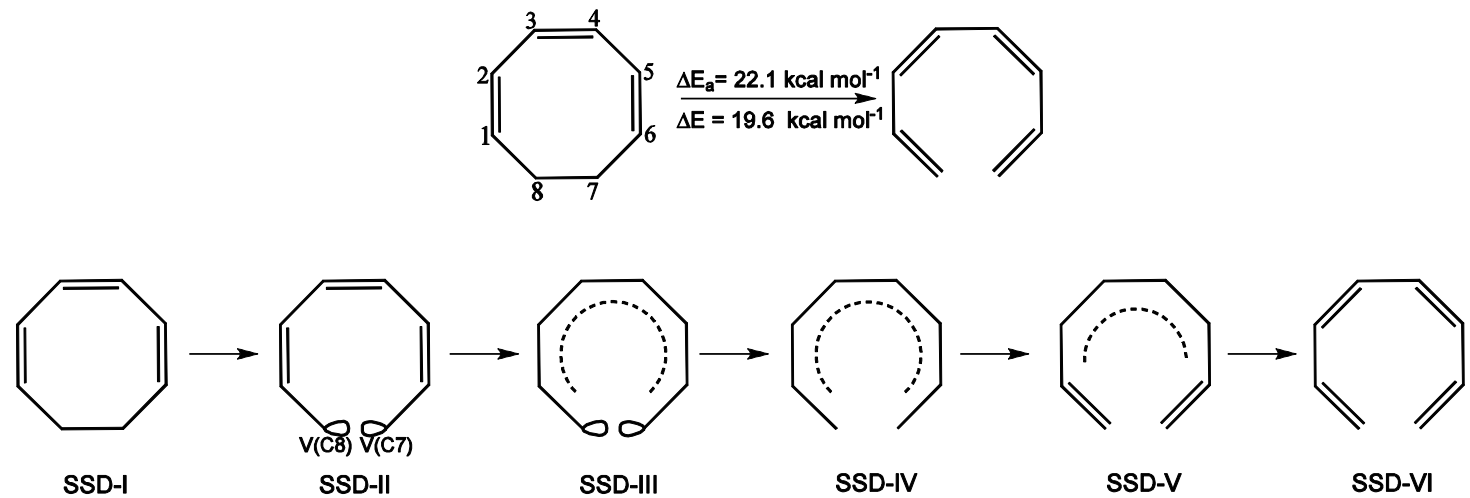

Figure 4. Thermal ring aperture for (1Z,3Z,5Z)-cycloocta-1,3,5-triene to (3Z,5Z)-octa-1,3,5,7tetraene and the corresponding representation of the SSDs from the perspective of the ELF analysis calculated at the DFT level of calculation. Full lines and ellipses represent disynaptic and monosynaptic basins. Dashed lines indicate a large basin population. 


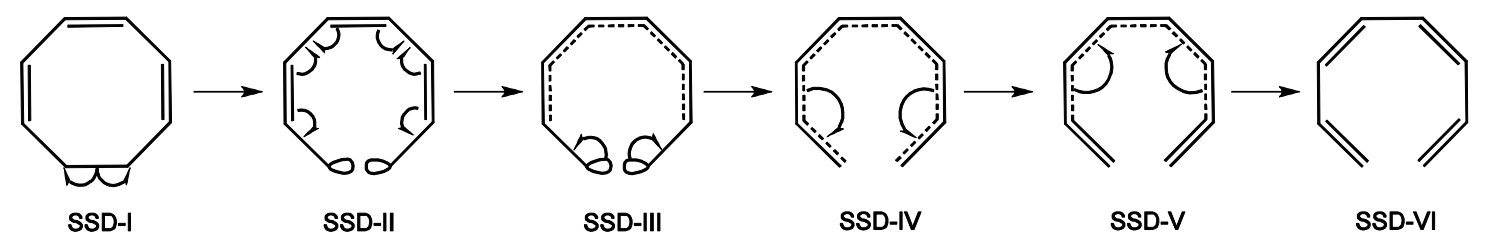

Scheme 4

\section{References}

1. I. Langmuir, Science, 1921, 54, 59-67.

2. N. V. Sidgwick, J. Chem. Soc. Trans., 1923, 123, 725-730.

3. C. R. Bury, J. Am. Chem. Soc., 1921, 43, 1602-1609.

4. A. A. Blanchard and W. L. Gilliland, J. Am. Chem. Soc., 1926, 48, 872-882.

5. C. K. Ingold, J. Chem. Soc., 1922, 121, 1133-1143.

6. C. K. Ingold, J. Chem. Soc., 1933, 143, 1120-1127.

7. N. V. Sidgwick and H. M. Powell, Proc. R. Soc. A, 1940, 176, 153-180.

8. R. J. Gillespie and R. S. Nyholm, Quart. Rev. Chem. Soc., 1957, 11, 339-380.

9. R. J. Gillespie, Molecular Geometry Van Nostrand Reinhold Comp., London, 1972.

10. R. J. Gillespie, Chem. Soc. Rev., 1991, 21, 59-69.

11. R. J. Gillespie and E. A. Robinson, Angew. Chem. Int. Ed. Engl., 1996, 35, 495-514.

12. P. Ball, Nature, 2011, 469, 26-28.

13. M. Jansen and U. Wedig, Angewandte Chemie International Edition, 2008, 47, 10026-10029.

14. J. F. Gonthier, S. N. Steinmann, M. D. Wodrich and C. Corminboeuf, Chemical Society Reviews, 2012, 41, 4671-4687.

15. G. Frenking and S. Shaik, editors, J. Comput. Chem., 2007, 28, 1-466.

16. G. Frenking and A. Krapp, J. Comput. Chem., 2007, 28, 15-24.

17. A. L. Fetter and J. D. Walecka, Quantum theory of many-particle systems, Dover Publications, Mineola (New York), 1st Dover edn., 2003.

18. R. D. Mattuck, A guide to Feynman diagrams in the many-body problem, Dover Publications, New York, 2nd edn., 1992.

19. P. O. Lowdin, Theochem, 1991, 76, 1-3.

20. P. V. Schleyer, Chemical Reviews, 2005, 105, 3433-3435.

21. P. L. A. Popelier, Faraday Discussions, 2007, 135, 3-5.

22. I. V. Alabugin, K. M. Gilmore and P. W. Peterson, Wiley Interdisciplinary Reviews-Computational Molecular Science, 2011, 1, 109-141.

23. S. K. Ritter, Chem. Eng. News, 2013, 91, 28-33.

24. W. Kutzelnigg, in Theoretical Models of Chemical Bonding: Part 2, ed. Z. B. Maksic, SpringerVerlag, Berlin, 1990, pp. 1-43.

25. S. Álvarez, R. Hoffmann and C. Mealli, Chem. Eur. J., 2009, 15, 8358-8373.

26. D. Danovich, P. C. Hiberty, W. Wu, H. S. Rzepa and S. Shaik, Chem. Eur. J., 2014, 20, 6220-6232.

27. M. Born and K. Huang, Dynamical Theory of Crystal Lattices, Oxford University Press, Oxford, 1985 .

28. M. Born and J. R. Oppenheimer, Ann. Phys., 1927, 84, 457-484.

29. J. C. Slater, Proc. Natl. Acad. Sci. U. S. A., 1927, 13, 423-430.

30. P. Atkins and R. Friedman, Molecular quantum mechanics, Oxford University Press, Oxford, 4th edn., 2005.

31. D. Wales, Energy Landscapes: Applications to Clusters, Biomolecules and Glasses, Cambridge University Press, Cambridge, 2003.

32. Z. Konkoli, E. Kraka and D. Cremer, J. Phys. Chem. A, 1997, 101, 1742-1757.

33. D. Cremer and E. Kraka, Curr. Org. Chem., 2010, 14, 1524-1560.

34. E. Kraka and D. Cremer, Acc. Chem. Res., 2010, 43, 591-601.

35. E. Kraka, H. Joo and D. Cremer, Mol. Phys., 2010, 108, 2667-2685.

36. N. Pavliček, B. Schuler, S. Collazos, N. Moll, D. Pérez, E. Guitián, G. Meyer, D. Peña and L. Gross, Nat. Chem., 2015, 7, 623-628.

37. B. Schuler, S. Fatayer, F. Mohn, N. Moll, N. Pavliček, G. Meyer, D. Peña and L. Gross, Nat. Chem., 2016, 8, 220-224. 
38. P. Arrowsmith, F. E. Bartoszek, S. H. P. Bly, T. Carrington, P. E. Charters and J. C. Polanyi, J. Chem. Phys., 1980, 73, 5895-5897.

39. P. Hering, P. R. Brooks, R. F. Curi, R. S. Judson and R. S. Lowe, Phys. Rev. Lett., 1980, 44, 687690.

40. A. H. Zewail, Science, 1988, 242, 1645-1653.

41. D. M. Newmark, Annual Review of Physical Chemistry, 1992, 43, 153-176.

42. P. G. Wenthold, D. A. Hrovat, W. T. Borden and W. C. Lineberger, Science, 1996, 272, 1456-1459.

43. Y. Mo, L. Song, W. E. I. Wu, Z. Cao and Q. Zhang, Journal of Theoretical and Computational Chemistry, 2002, 01, 137-151.

44. J. P. Foster and F. Weinhold, Journal of the American Chemical Society, 1980, 102, 7211-7218.

45. K. Fukui, T. Yonezawa and H. Shingu, J. Chem. Phys., 1952, 20, 722-725.

46. R. F. W. Bader, Atoms in molecules: a quantum theory, Oxford University Press, Oxford, 1990.

47. R. F. W. Bader, Chem. Rev., 1991, 91, 893-928.

48. P. C. Hohenberg and W. Kohn, Phys. Rev. , 1964, 136, B864-B871.

49. W. Kohn and L. J. Sham, Phys. Rev., 1965, 140, A1133-A1138.

50. R. G. Parr and W. T. Yang, Annual Review of Physical Chemistry, 1995, 46, 701-728.

51. P. Geerlings, F. De Proft and W. Langenaeker, Chemical Reviews, 2003, 103, 1793-1873.

52. F. Neese, Angew. Chem. Int. Ed., 2017, 56, 2-10.

53. J. M. Solano-Altamirano and J. M. Hernández-Pérez, Computer Physics Communications, 2015, 196, 362-371.

54. S. Álvarez, Angew. Chem. Int. Ed., 2012, 51, 590-600.

55. D. Himmel, I. Krossing and A. Schnepf, Angew. Chem. Int. Ed. Engl., 2014, 53, 370-374.

56. W. O. Kermack and R. Robinson, J. Chem. Soc. Trans., 1922, 121, 427-440.

57. C. K. Ingold, Chem. Rev., 1934, 15, 225-274.

58. D. O'Hagan and D. Lloyd, Chemistry World, 2010, 7, 54-57.

59. R. B. Grossman, The art of writing reasonable organic reaction mechanisms, Springer-Verlag, New York, 2nd edn., 2003.

60. V. Gineityte, Int. J. Quantum Chem., 2003, 94, 302-316.

61. V. Gineityte, Z. Naturforsch A, 2009, 64a, 132-148.

62. V. Gineityte, Lithuanian journal of physics, 2011, 51, 107-126.

63. J. A. Berson, in Rearrangements in ground and excited states, ed. P. de Mayo, Academic Press, New York, 1980, vol. 1, p. 311.

64. T. H. Lowry and K. S. Richardson, Mechanism and theory in organic chemistry, Harper \& Row, New York, 1987.

65. J. J. Gajewski, Hydrocarbon thermal isomerizations, Elsevier, Amsterdam, 2004.

66. E. V. Anslyn and D. A. Dougherty, Modern Physical Organic Chemistry, University Science Books, Sausalito, CA, 2006.

67. M. B. Smith, March's Advanced Organic Chemistry: Reactions, Mechanisms, and Structure, Wiley, Hoboken, 7th edn., 2013.

68. K. P. C. Vollhardt and N. E. Schore, Organic Chemistry: structure and function, W. H. Freeman, New York, 5th edn., 2007.

69. R. G. Wilkins, Kinetics and mechanism of reactions of transition metal complexes, Wiley-VCH Verlag, Weinheim, Germany, 2nd edn., 2003.

70. R. B. Jordan, Reaction mechanisms of inorganic and organometallic systems, Oxford University Press, Oxford, 3rd edn., 2007.

71. C. K. Mathews, K. E. van Holde and K. G. Ahern, Biochemistry, Prentice-Hall, Upper Saddle River, NJ, 3rd edn., 1999.

72. D. L. Nelson and M. M. Cox, Lehninger principles of biochemistry, W. H. Freeman and Company, New York, 5th edn., 2008.

73. J. Keeler and P. Wothers, Chemical structure and reactivity: an integrated approach, Oxford University Press, Oxford, 2013.

74. S. M. Bachrach, Computational organic chemistry, Wiley, Hoboken, 2014.

75. G. Knizia and J. E. M. N. Klein, Angew. Chem. Int. Ed., 2015, 54, 1-6.

76. G. N. Lewis, J. Am. Chem. Soc., 1916, 38, 762-785.

77. L. Pauling, J. Am. Chem. Soc., 1931, 53, 1367-1400.

78. L. Pauling, J. Am. Chem. Soc., 1931, 53, 3225-3237.

79. L. Pauling, J. Am. Chem. Soc., 1932, 54, 988-1003. 
80. L. Pauling, The nature of the chemical bond, Cornell University Press, Ithaca, 1948.

81. S. Shaik and A. Shurki, Angew. Chem. Int. Ed., 1999, 38, 586-625.

82.

83.

84.

85.

86.

A. Shurki, E. Derat, A. Barrozo and S. C. L. Kamerlin, Chem. Soc. Rev., 2015, 44, 1037-1052.

M. Okuyama and K. Takatsuka, Chem. Phys. Letters, 2009, 476, 109-115.

A. Schild, F. Agostini and E. K. U. Gross, J. Phys. Chem. A, 2016, 120, 3316-3325.

T. Bredtmann, J. Manz and J.-M. Zhao, J. Phys. Chem. A, 2016, 120, 3142-3154.

M. Berg, B. Paulus and T. Bredtmann, Mol. Phys., 2016, 114, 1356-1364.

87. T. Bredtmann, D. J. Diestler, S.-D. Li, J. Manz, J. F. Pérez-Torres, T. Wen-Juan, Y.-B. Wu, Y. Yonggang and H.-J. Zhai, Phys. Chem. Chem. Phys., 2015, 17, 29421-29464.

88. T. Bredtmann, M. Ivanov and G. Dixit, Nat Commun, 2014, 5, 5589.

89. T. Bredtmann and B. Paulus, J. Chem. Theor. Comput., 2013, 9, 3026-3034.

90. T. Bredtmann, H. Kono, J. Manz, K. Nakamura and C. Stemmle, ChemPhysChem, 2013, 14, 13971404.

91. D. J. Diestler and J. Beyond, J. Phys. Chem. A, 2013, 117, 4698-4708.

92. T. Bredtmann, E. Hupf and B. Paulus, Phys. Chem. Chem. Phys., 2012, 14, 15494-15501.

93. D. Andrae, I. Barth, T. Bredtmann, H.-C. Hege, J. Manz, F. Marquardt and B. Paulus, The Journal of Physical Chemistry B, 2011, 115, 5476-5483.

94. T. Bredtmann and J. Manz, Angewandte Chemie-International Edition, 2011, 50, 12652-12654.

95. P. Emma, R. Akre, J. Arthur, R. Bionta, C. Bostedt, J. Bozek, A. Brachmann, P. Bucksbaum, R. Coffee, F.-J. Decker, Y. Ding, D. Dowell, S. Edstrom, A. Fisher, J. Frisch, S. Gilevich, J. Hastings, G. Hays, P. Hering, Z. Huang, R. Iverson, H. Loos, M. Messerschmidt, A. Miahnahri, S. Moeller, H.-D. Nuhn, G. Pile, D. Ratner, J. Rzepiela, D. Schultz, T. Smith, P. Stefan, H. Tompkins, J. Turner, J. Welch, W. White, J. Wu, Y. G. and J. Galayda, Nature Photonics, 2010, 4, 641-647.

96. T. Ishikawa, H. Aoyagi, T. Asaka, Y. Asano, N. Azumi, T. Bizen, H. Ego, K. Fukami, T. Fukui, Y. Furukawa, S. Goto, H. Hanaki, T. Hara, T. Hasegawa, T. Hatsui, A. Higashiya, T. Hirono, N. Hosoda, M. Ishii, T. Inagaki, Y. Inubushi, T. Itoga, Y. Joti, M. Kago, T. Kameshima, H. Kimura, Y. Kirihara, A. Kiyomichi, T. Kobayashi, C. Kondo, T. Kudo, H. Maesaka, X. M. Marechal, T. Masuda, S. Matsubara, T. Matsumoto, T. Matsushita, S. Matsui, M. Nagasono, N. Nariyama, H. Ohashi, T. Ohata, T. Ohshima, S. Ono, Y. Otake, C. Saji, T. Sakurai, T. Sato, K. Sawada, T. Seike, K. Shirasawa, T. Sugimoto, S. Suzuki, S. Takahashi, H. Takebe, K. Takeshita, K. Tamasaku, H. Tanaka, R. Tanaka, T. Tanaka, T. Togashi, K. Togawa, A. Tokuhisa, H. Tomizawa, K. Tono, S. Wu, M. Yabashi, M. Yamaga, A. Yamashita, K. Yanagida, C. Zhang, T. Shintake, H. Kitamura and N. Kumagai, Nat Photon, 2012, 6, 540-544.

97. I. McKinnie and H. Kapteyn, Nat Photon, 2010, 4, 149-151.

98. M. Aidelsburger, F. O. Kirchner, F. Krausz and P. Baum, Proceedings of the National Academy of Sciences, 2010, 107, 19714-19719.

99. S. Germán and R. J. D. Miller, Reports on Progress in Physics, 2011, 74, 096101.

100. I. Iwakura and A. Yabushita, Bulletin of the Chemical Society of Japan, 2015, 89, 296-307.

101. M. Abe, I. Iwakura, A. Yabushita, S. Yagi, J. Liu, K. Okamura and T. Kobayashi, Chemical Physics Letters, 2012, 527, 79-83.

102. I. Iwakura, A. Yabushita, J. Liu, K. Okamura and T. Kobayashi, Physical Chemistry Chemical Physics, 2012, 14, 9696-9701.

103. I. Iwakura, A. Yabushita and T. Kobayashi, Chemical Physics Letters, 2011, 501, 567-571.

104. I. Iwakura, Y. Kaneko, S. Hayashi, A. Yabushita and T. Kobayashi, Molecules, 2013, 18, $1995-$ 2004.

105. I. Iwakura, A. Yabushita, J. Liu, K. Okamura, S. Kezuka and T. Kobayashi, Pure \& Appl. Chem., 2013, 85, 1991-2004.

106. I. Iwakura, Physical Chemistry Chemical Physics, 2011, 13, 5546-5555.

107. I. Iwakura, A. Yabushita and T. Kobayashi, Chemistry Letters, 2010, 39, 374-375.

108. K. Fukui, Science, 1982, 218, 747-754.

109. R. B. Woodward and R. Hoffmann, J. Am. Chem. Soc., 1965, 87, 395-397.

110. R. Hoffmann, Angew. Chem. Int. Ed. Engl., 1982, 21, 711-724.

111. R. Hoffmann, Angew. Chem., 1982, 94, 725-739.

112. A. Toro-Labbé, J. Phys. Chem. A, 1999, 103, 4398-4403.

113. B. Herrera and A. Toro-Labbé, J. Chem. Phys., 2004, 121, 7096-7102.

114. S. Gutiérrez-Oliva, B. Herrera, A. Toro-Labbé and H. Chermette, J. Phys. Chem. A, 2005, 109, 1748-1751. 
115. J. Martínez and A. Toro-Labbé, Chem. Phys. Letters, 2004, 392, 132-139.

116. A. Toro-Labbé, S. Gutiérrez-Oliva, M. Concha, P. Murray and J. Politzer, J. Chem. Phys., 2004, 121, 4570-4575.

117. B. Herrera and A. Toro-Labbé, J. Phys. Chem. A, 2008, 111, 5921-5926.

118. E. Echegaray and A. Toro-Labbé, J. Phys. Chem. A, 2008, 112, 11801-11807.

119. M. L. Cerón, E. Echegaray, S. Gutiérrez-Oliva, B. Herrera and A. Toro-Labbé, Sci. China Chem., 2011, 54, 1982-1988.

120. S. Giri, E. Echegaray, P. W. Ayers, A. S. Núñez, F. Lund and A. Toro-Labbé, J. Phys. Chem. A, 2011, 116, 10015-10026.

121. M. L. Cerón, B. Herrera, P. Araya, F. Gracia and A. Toro-Labbé, J. Mol. Model., 2011, 17, 16251633.

122. S. Gómez, D. Guerra, J. G. López, A. Toro-Labbé and A. Restrepo, J. Phys. Chem. A, 2013, 117, 1991-1999.

123. G. Knizia, J. Chem. Theory Comput., 2013, 9, 4834-4843.

124. J. E. M. N. Klein, B. Miehlich, M. S. Holzwarth, M. Bauer, M. Milek, M. M. Khusniyarov, G. Knizia, H.-J. Werner and B. Plietker, Angew. Chem. Int. Ed., 2014, 53, 1790-1794.

125. J. E. M. N. Klein, B. Miehlich, M. S. Holzwarth, M. Bauer, M. Milek, M. M. Khusniyarov, G. Knizia, H.-J. Werner and B. Plietker, Angew. Chem., 2014, 126, 1820-1824.

126. F. S. Vieira, F. Fantuzzi, T. M. Cardozo and M. A. Chaer Nascimento, Journal of Physical Chemistry A, 2013, 117, 4025-4034.

127. R. F. W. Bader and W. H. Henneker, Journal of the American Chemical Society, 1965, 87, 30633068 .

128. G. Sini, P. Maitre, P. C. Hiberty and S. S. Shaik, Theochem-Journal of Molecular Structure, 1991, 75, 163-188.

129. D. B. Chesnut, Journal of Chemical Theory and Computation, 2008, 4, 1637-1642.

130. S. Shaik, D. Danovich, W. Wu and P. C. Hiberty, Nature Chemistry, 2009, 1, 443-449.

131. J. A. Gamez and M. Yáñez, Journal of Chemical Theory and Computation, 2013, 9, 5211-5215.

132. W. A. Goddard, III and L. B. Harding, The description of chemical bonding from ab initio calculations, 1978.

133. A. Kovacs, C. Esterhuysen and G. Frenking, Chemistry-a European Journal, 2005, 11, 1813-1825.

134. P. L. Ayers, R. J. Boyd, P. Bultink, M. Caffarel, R. Carbó-Dorca, M. Causá, J. Cioslowski, J.

Contreras-García, D. L. Cooper, P. Coppens, C. Gatti, S. Grabowsky, P. Lazzaretti, P. Macchi, A. Martín-Pendás, P. L. A. Popelier, K. Ruedenberg, H. Rzepa, A. Savin, A. Sax, W. H. E. Schwarz, S. Shahbazian, B. Silvi, M. Solà and V. Tsirelson, Comput. Theor. Chem., 2015, 1053, 2-16.

135. R. Abraham and J. E. Marsden, Foundations of mechanics, Addison Wesley, Redwood City, 1994.

136. P. L. A. Popelier, in Structure and bonding, ed. D. J. Wales, Springer-Verlag, Berlin, 2005, vol. 115, pp. 1-56.

137. P. L. A. Popelier and E. A. G. Bremond, International Journal of Quantum Chemistry, 2009, 109, 2542-2553.

138. S. Noury, X. Krokidis, F. Fuster and B. Silvi, Computers \& Chemistry, 1999, 23, 597-604.

139. P. L. A. Popelier, Computer Physics Communications, 1996, 93, 212-240.

140. M. Kohout, Chemical Bonding Analysis in Direct Space).

141. F. Biegler-Konig, J. Schonbohm and D. Bayles, Journal of Computational Chemistry, 2001, 22, 545559.

142. A. Otero-de-la-Roza, M. A. Blanco, A. M. Pendas and V. Luana, Computer Physics Communications, 2009, 180, 157-166.

143. R. J. Gillespie and P. L. A. Popelier, Chemical bonding and molecular geometry: from Lewis to electron densities, Oxford University Press, New York, 2001.

144. B. Silvi and A. Savin, Nature, 1994, 371, 683-686.

145. B. de Courcy, L. G. Pedersen, O. Parisel, N. Gresh, B. Silvi, J. Pilme and J. P. Piquemal, Journal of Chemical Theory and Computation, 2010, 6, 1048-1063.

146. J. Pilme, H. Berthoumieux, V. Robert and P. Fleurat-Lessard, Chemistry-a European Journal, 2007, 13, 5388-5393.

147. A. de la Lande, J. Maddaluno, O. Parisel, T. A. Darden and J. P. Piquemal, Interdisciplinary Sciences-Computational Life Sciences, 2010, 2, 3-11.

148. S. Berski, J. Andrés, B. Silvi and L. R. Domingo, J. Phys. Chem. A, 2006, 110, 13939-13947.

149. J. Poater, M. Duran, M. Sola and B. Silvi, Chemical Reviews, 2005, 105, 3911-3947. 
150. F. Pauzat, J. Pilme, J. Toulouse and Y. Ellinger, Journal of Chemical Physics, 2010, 133, 054301054306.

151. P. Rivera-Fuentes, J. L. Aonso-Gomez, A. G. Petrovic, P. Seiler, F. Santoro, N. Harada, N. Berova, H. S. Rzepa and F. Diederich, Chemistry-a European Journal, 2010, 16, 9796-9807.

152. D. Kozlowski and J. Pilmé, J. Comput. Chem., 2011, 32, 3207-3217.

153. S. Jenkins, International Journal of Quantum Chemistry, 2013, 113, 1603-1608.

154. T. S. Koritsanszky and P. Coppens, Chem. Rev., 2001, 101, 1583-1628.

155. P. Coppens, X-ray charge densities and chemical bonding, Oxford University Press, Oxford, 1997.

156. P. L. Popelier, Atoms in molecules: an introduction, Pearson Education, Harlow, 2000.

157. V. G. Tsirelson and R. P. Ozerov, Electron density and bonding in crystals, Institute of physics publishing, Bristol, 1996.

158. G. A. Jeffrey and J. F. Piniella, The applications of charge density research to chemistry and drug design, Springer, New York, 1991.

159. C. F. Matta and R. J. Boyd, The Quantum theory of atoms in molecules : from solid state to DNA and drug design, Wiley-VCH, Weinheim, 2007.

160. D. Stalke, Chem. Eur. J., 2011, 17, 9264-9278.

161. C. Gatti and P. Macchi, Modern charge density analysis, Springer, New York, 2012.

162. D. Chopra, Journal of Physical Chemistry A, 2012, 116, 9791-9801.

163. A. M. Pendás and J. Hernández-Trujillo, J. Chem. Phys., 2012, 137, 134101.

164. J. Dillen, J. Comput. Chem., 2015, 36, 883-890.

165. R. F. W. Bader, Phys. Rev. B, 1994, 49, 13348-13356.

166. A. D. Becke and K. E. Edgecombe, J. Chem. Phys., 1990, 92, 5397-5403.

167. R. F. W. Bader, P. L. A. Popelier and T. A. Keith, Angewandte Chemie International Edition in English, 1994, 33, 620-631.

168. C. L. Firme, N. B. P. Barreiro, P. M. Esteves and R. J. Correa, J. Phys. Chem. A, 2008, 112, 686694.

169. H. Rzepa, J. Chem. Theor. Comput., 2011, 7, 97-102.

170. A. Otero de la Roza and V. Luaña, J. Chem. Theor. Comput., 2010, 6, 3761-3779.

171. A. Otero de la Roza and V. Luaña, J. Phys. Chem. A, 2011, 115, 12953-12961.

172. I. Vidal and A. Sánchez Navas, J. Mol. Model., 2014, 20, 2425-2433.

173. S. J. Grabowsky, J. Phys. Chem. A, 2012, 116, 1838-1845.

174. S. Jenkins, C. Rong, S. R. Kirk, D. Yin and S. Liu, J. Phys. Chem. A, 2011, 115, 12503-12511.

175. K. Mierzwicki, S. Berski and Z. Latajka, Chem. Phys. Letters, 2011, 507, $29-36$.

176. O. A. Syzgantseva, V. Tognetti and L. Loubert, J. Phys. Chem. A, 2013, 117, 8969-8980.

177. J. Andrés, L. Gracia, P. Gonzalez-Navarrete and V. S. Safont, Computational and Theoretical Chemistry, 2015, 1053, 17-30.

178. M. García-Revilla, P. L. A. Popelier, E. Francisco and A. Martín-Pendás, J. Chem. Theor. Comput., 2011, 7, 1704-1711.

179. G. S. Heverly-Coulson and R. J. Boyd, J. Chem. Theor. Comput., 2012, 8, 5052-5057.

180. A. Savin, O. Jepsen, J. Flad, O. K. Andersen, H. Preuss and H. G. v. Schnering, Angew. Chem. Int. Ed. Engl., 1992, 31, 187-188.

181. A. Savin, R. Nesper, S. Wengert and T. F. Fässler, Angew. Chem. Int. Ed. Engl., 1997, 36, 18081832 .

182. D. B. Chesnut, J. Phys. Chem. A, 2000, 104, 11644-11650.

183. A. Savin, A. D. Becke, J. Flad, R. Nesper, H. Preuß and H. G. von Schnering, Angew. Chem. Int. Ed. Engl., 1991, 30, 409-412.

184. J. K. Burdett and T. A. McCormick, J. Phys. Chem. A, 1998, 102, 6366-6372.

185. R. F. Nalewajski, A. M. Koster and S. Escalante, J. Phys. Chem. A, 2005, 109, 10038-10043.

186. J. F. Dobson, J. Chem. Phys., 1991, 94, 4238-4333.

187. M. Kohout, K. Pernal, F. R. Wagner and Y. Grin, Theor. Chem. Acc., 2004, 112, 453-459.

188. F. R. Wagner, V. Bezugly, M. Kohout and Y. Grin, Chem. Eur. J., 2007, 13, 5724-5741.

189. B. Silvi, Journal of Physical Chemistry A, 2003, 107, 3081-3085.

190. E. Matito, B. Silvi, M. Duran and M. Solà, Journal of Chemical Physics, 2006, 125, 024301(024301024309).

191. F. Feixas, E. Matito, M. Duran, M. Solà and B. Silvi, Journal of Chemical Theory and Computation, 2010, 6, 2736-2742.

192. B. Silvi, I. Fourre and M. E. Alikhani, Monatshefte Fur Chemie, 2005, 136, 855-879. 
193. B. Silvi and H. Ratacjak, Phys. Chem. Chem. Phys., 2016, 18, 27442-27449.

194. P. W. Ayers, J. Chem. Sci., 2005, 117, 441-454.

195. P. Fuentealba, E. Chamorro and J. C. Santos, Theor. Comp. Chem., 2007, 19, 57-85.

196. B. Silvi, Phys. Chem. Chem. Phys., 2004, 6, 256-260.

197. B. Silvi, in The Chemical Bond II: 100 Years Old and Getting Stronger, ed. D. M. P. Mingos, Springer International Publishing, Cham, 2016, pp. 213-247.

198. V. Polo, J. Andres, S. Berski, L. R. Domingo and B. Silvi, Journal of Physical Chemistry A, 2008, 112, 7128-7136.

199. F. Cortés-Guzmán, R. M. Gómez, T. Rocha-Rinza, M. A. Sánchez-Obregón and J. M. Guevara-Vela, J. Phys. Chem. A, 2011, 115, 12924-12932.

200. R. F. W. Bader, P. J. MacDougall and C. D. H. Lau, J. Am. Chem. Soc., 1984, 106, 1594-1605.

201. S. Calvo-Losada, M. S. Pino-González and J. J. Quirante, J. Phys. Chem. B, 2015, 119, 1243-1258.

202. R. Thom, Nature, 1977, 270, 658-658.

203. X. Krokidis, S. Noury and B. Silvi, J. Phys. Chem. A, 1997, 101, 7277-7282.

204. R. Thom, Structural stability and morphogenesis, W. A. Benjamin Inc., Redding, 1976.

205. B. Silvi, Journal of Molecular Structure, 2002, 614, 3-10.

206. R. Thom, Structural stability and morphogenesis, an outline of a general theory of models, W. A. Benjamin, Reading, Massachusetts, 1st edn., 1975.

207. X. Y. Li, Y. L. Zeng, L. P. Meng and S. J. Zheng, J. Phys. Chem. A, 2007, 111, 1530-1535.

208. X. Li, H. Fan, L. Meng, Y. Zeng and S. Zheng, J. Phys. Chem. A, 2007, 111, 2343-2350.

209. Y. Zeng, S. Zheng and L. Meng, Inorg. Chem., 2004, 43, 5311-5320.

210. Y. Zeng, S. Zheng and L. Meng, J. Phys. Chem. A, 2004, 108, 10527-10534.

211. Y. L. Zeng, L. P. Meng and S. J. Zheng, J. Mol. Struct., 2004, 684, 103-110.

212. P. Macchi and A. Sironi, Coord. Chem. Rev., 2003, 238, 383-412.

213. N. O. Malcom and P. L. A. Popelier, J. Phys. Chem. A, 2001, 105, 7638-7645.

214. V. Polo, J. Andrés, R. Castillo, S. Berski and B. Silvi, Chem. Eur. J., 2004, 10, 5165-5172.

215. S. Berski, J. Andres, B. Silvi and L. R. Domingo, Journal of Physical Chemistry A, 2003, 107, 60146024.

216. J. Andrés, S. Berski, M. Feliz, R. Llusar, F. Sensato and B. Silvi, C. R. Chim., 2005, 8, 1400-1412.

217. J. Andres, S. Berski, L. R. Domingo and P. Gonzalez-Navarrete, Journal of Computational Chemistry, 2012, 33, 748-756.

218. J. Andres, S. Berski, L. R. Domingo, V. Polo and B. Silvi, Current Organic Chemistry, 2011, 15, 3566-3575.

219. V. Polo and J. Andres, Journal of Computational Chemistry, 2005, 26, 1427-1437.

220. V. Polo, L. R. Domingo and J. Andrés, J. Phys. Chem. A, 2005, 109, 10438-10444.

221. V. Polo, P. Gonzalez-Navarrete, B. Silvi and J. Andres, Theoretical Chemistry Accounts, 2008, 120, 341-349.

222. P. González-Navarrete, L. R. Domingo, J. Andrés, S. Berski and B. Silvi, J. Comput. Chem., 2012, 33, 2400-2411.

223. J. C. Santos, J. Andres, A. Aizman, P. Fuentealba and V. Polo, Journal of Physical Chemistry A, 2005, 109, 3687-3693.

224. J. Kalinowski, S. Berski and A. J. Gordon, Journal of Physical Chemistry A, 2011, 115, 1351313522.

225. S. Chiodo, O. Kondakova, M. D. Michelini, N. Russo and E. Sicilia, Inorganic Chemistry, 2003, 42, 8773-8782.

226. M. D. Michelini, E. Sicilia, N. Russo, M. E. Alikhani and B. Silvi, Journal of Physical Chemistry A, 2003, 107, 4862-4868.

227. S. Chiodo, O. Kondakova, M. D. Michelini, N. Russo, E. Sicilia, A. Irigoras and J. M. Ugalde, Journal of Physical Chemistry A, 2004, 108, 1069-1081.

228. M. E. Alikhani, M. d. C. Michelini, N. Russo and B. Silvi, J. Phys. Chem. A, 2008, 112, 1296612974.

229. S. Berski, F. R. Sensato, V. Polo, J. Andres and V. S. Safont, Journal of Physical Chemistry A, 2011, 115, 514-522.

230. P. Gonzalez-Navarrete, F. Sensato, J. Andrés and E. Longo, The Journal of Physical Chemistry A, 2014, 118, 6092-6103.

231. J. Andrés, P. González-Navarrete and V. S. Safont, International Journal of Quantum Chemistry, 2014, 114, 1239-1252. 
232. N. Gillet, R. Chaudret, J. Contreras-García, W. Yang, B. Silvi and J.-P. Piquemal, J. Chem. Theor. Comput., 2012, 8, 3993-3997.

233. J. Andres, S. Berski, J. Contreras-Garcia and P. Gonzalez-Navarrete, Journal of Physical Chemistry $A, 2014,118,1663-1672$.

234. I. Viciano, P. González-Navarrete, J. Andrés and S. Martí, J. Chem. Theor. Comput., 2015, 11, 14701480 .

235. D. Fang, R. Chaudret, J.-P. Piquemal and G. A. Cisneros, Journal of Chemical Theory and Computation, 2013, 9, 2156-2160.

236. J. Andrés, L. Gracia, P. González-Navarrete and V. S. Safont, in Applications of Topological Methods in Molecular Chemistry, eds. R. Chauvin, C. Lepetit, B. Silvi and E. Alikhani, Springer International Publishing, Switzerland, 2016, ch. 10, pp. 257-294.

237. J. Andrés, S. Berski and B. Silvi, Chem. Commun., 2016, 52, 8183-8195.

238. B. Silvi and R. J. Gillespie, in The Quantum Theory of Atoms in Molecules, Wiley-VCH Verlag GmbH \& Co. KGaA, 2007, pp. 141-162.

239. B. Silvi, M. E. Alikhani, C. Lepetit and R. Chauvin, in Applications of Topological Methods in Molecular Chemistry, eds. R. Chauvin, C. Lepetit, B. Silvi and E. Alikhani, Springer International Publishing, Switzerland, 2016, ch. 1, pp. 1-20.

240. Y. Grin, A. Savin and B. Silvi, in The Chemical Bond: Fundamental Aspects of Chemical Bonding, eds. G. Frenking and S. Shaik, Wiley-VCH Verlag GmbH \& Co, KGaA, Weinheim, Germany, 2014.

241. P. González-Navarrete, J. Andrés and S. Berski, J. Phys. Chem. Lett., 2012, 3, 2500-2505.

242. T. Bredtmann and J. Manz, Journal of Chemical Sciences, 2012, 124, 121-129.

243. E. C. Brown, R. F. W. Bader and N. H. Werstiuk, The Journal of Physical Chemistry A, 2009, 113, 3254-3265.

244. R. S. Mulliken, Physical Review, 1928, 32, 186-222.

245. W. Heitler and F. London, Zeitschrift fur Physik, 1927, 44, 455-472. 